\title{
Optimal Planning and Operation of Aggregated Distributed Energy Resources with Market Participation
}

\author{
C. F. Calvillo ${ }^{1 *}$, A. Sánchez-Miralles ${ }^{1}$, J. Villar ${ }^{1}$, F. Martín ${ }^{1}$ \\ ${ }^{1}$ Institute for Research in Technology (IIT) \\ ICAI School of Engineering, Comillas Pontifical University \\ Santa Cruz de Marcenado 26, 28015, Madrid, Spain
}

\section{* Corresponding author}

Email addresses: christian.calvillo@iit.comillas.edu (C.F. Calvillo), alvaro@comillas.edu (A. Sánchez-Miralles), jose.villar@iit.comillas.edu (J. Villar), francisco.martin@iit.comillas.edu (F. Martín).

\section{Abstract}

This paper analyzes the optimal planning and operation of aggregated distributed energy resources (DER) with participation in the electricity market. Aggregators manage their portfolio of resources in order to obtain the maximum benefit from the grid, while participating in the day-ahead wholesale electricity market. The goal of this paper is to propose a model for aggregated DER systems planning, considering its participation in the electricity market and its impact on the market price. The results are the optimal planning and management of DER systems, and the appropriate energy transactions for the aggregator in the wholesale day-ahead market according to the size of its aggregated resources. A price-maker approach based on representing the market competitors with residual demand curves is followed, and the impact on the price is assessed to help in the decision of using price-maker or price-taker approaches depending on the size of the aggregated resources. A deterministic programming problem with two case studies (the average scenario and the most likely scenario from the stochastic ones), and a stochastic one with a case 
C. Calvillo, A. Sánchez, J. Villar, F. Martín. Optimal planning and operation of aggregated distributed energy resources with market participation. Applied Energy. vol. 182, pp. 340-357, November 2016. [Online: August 2016] JCR impact factor: 7.182 (2016)

study to account for the market uncertainty are described. For both models, market scenarios have been built from historical data of the Spanish system.

The results suggest that when the aggregated resources have enough size to follow a price-maker approach and the uncertainty of the markets is considered in the planning process, the DER systems can achieve up to 50\% extra economic benefits, depending on the market share, compared with a non-aggregated business-as-usual approach (not implementing DER systems).

Keywords- Energy Management; Renewable Sources; Energy Storage; Aggregator; Energy System Models; Demand Response.

\section{Nomenclature}

Sets
$h$
$m$
$y$
$c$
$p$
seg
$s$
Parameters
pLifespan
pNumHouses
pHouseMultiplier
pDemandElec,$m_{, h}$
pDemandTherm ${ }_{c, m}$
pCost $E_{y}$
pCost $T_{y}$
pFixEpow
pFixTpow
pGridTariffEE
pDNI ${ }_{m, h}$
pLossesPV
pLossesHP
pCostPV
pCostHP

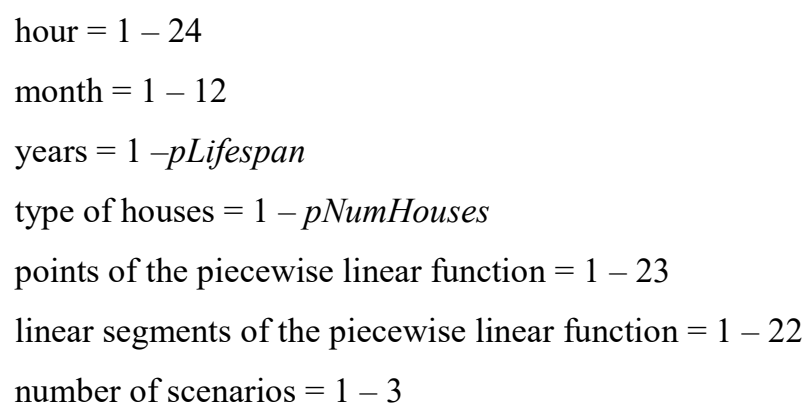

Expected lifespan for PV and HP systems in the study (years)

Number of different houses

Number of equivalent clients per house type

Base electric demand curve for 12 representative days (MWh) in each house

Total thermal demand for 12 representative days (MWh)

Electric energy base buying price at year $y(€ / \mathrm{MWh})$

Thermal energy base buying price at year $y(€ / M W h)$

Access tariff for electric power $(€ / \mathrm{MW})$

Access tariff for thermal power ( $€ /$ client)

Share of the variable electricity tariff that correspond to network costs ( $€ / \mathrm{MWh})$

Direct normal irradiance (W)

Total electric losses in the PV system (\%)

Total thermal losses in the HP system (\%)

Total cost per installed Watt of PV (€/MW)

Total cost per installed Watt of HP (electric power input) (€/MW) 
C. Calvillo, A. Sánchez, J. Villar, F. Martín. Optimal planning and operation of aggregated distributed energy resources with market participation. Applied Energy. vol. 182, pp. 340-357, November 2016. [Online: August 2016] JCR impact factor: 7.182 (2016)

\begin{tabular}{|c|c|}
\hline pCostBat & Total upfront cost of batteries, considering a replacement every 8 years ( $€ / \mathrm{MWh})$ \\
\hline pOMfixPV & Fixed annual Operation and Maintenance costs per installed Watt of PV (€/MW) \\
\hline pOMfixHP & Fixed annual Operation and Maintenance costs per installed Watt of HP (€/MW) \\
\hline$p C O P$ & Coefficient of Performance for the HP \\
\hline pDemandShift & Maximum allowed load to be shifted per day of the base electric demand (\%) \\
\hline pDRequipCost & Costs of equipment required in each house to do load shifting ( $€ /$ client) \\
\hline pDaysInMonth ${ }_{m}$ & Number of days in month $m$ \\
\hline pEffBat & Battery charge/discharge efficiency $(\%)$ \\
\hline probs $_{s, m, h}$ & Probabilities for each scenario and each hour $(\%)$ \\
\hline probAvg $_{s}$ & Average probabilities for each scenario $(\%)$ \\
\hline pXparameter $_{s, p, m, h}$ & "X" value (energy) of the point $p$ in the piecewise linear functions (MWh) \\
\hline pYparameter Yp $, m, h$ & "Y" value (energy cost) of the point $p$ in the piecewise linear functions ( $€ / M W h)$ \\
\hline pAvgSystemDemand $m, h$ & Average total system demand (MWh) \\
\hline \multicolumn{2}{|l|}{ Positive Variables } \\
\hline vPowerPV $V_{c}$ & PV installed capacity of (MW) \\
\hline$v$ BatCapacity $_{c}$ & Battery installed capacity(MWh) \\
\hline$v$ PowerHP & HP installed capacity (MW) \\
\hline$v \operatorname{ProdP} V_{c, m, h}$ & Electric PV production (MWh) \\
\hline$v$ ElecHPinput $t_{s, c, m, h}$ & Electricity for thermal production with HP (MWh) \\
\hline$v$ GridEnTotalPos ${ }_{s, m, h}$ & Total energy transaction to the grid (positive side) (MWh) \\
\hline vGridEnTotalNeg $g_{s, c, m, h}$ & Total energy transaction to the grid (negative side) (MWh) \\
\hline$v B o u g h t E n e r g y T_{s, c, m}$ & Thermal energy bought (natural gas) from the grid to meet the daily demand (MWh) \\
\hline$v S O C_{s, c, m, h}$ & Battery State-of-Charge (MWh) \\
\hline$v D i s B a t_{s, c, m, h}$ & Energy discharged from battery (MWh) \\
\hline$v C_{h B a t}, c, m, h$ & Energy charged to the battery (MWh) \\
\hline$v$ DecDemand $_{s, c, m, h}$ & Decrease in base demand from pDemandElec (MWh) \\
\hline$v_{\text {IncDemand }}, c, m, h$ & Increase in base demand from pDemandElec (MWh) \\
\hline$v$ DemandNew $w_{s, c, m, h}$ & New consumption curve after changing the base profile of $p$ DemandElec $(\mathrm{MWh})$ \\
\hline vPowElect s,c $_{2}$ & contracted annual electric power in house $c(\mathrm{MW})$ \\
\hline$v G r i d \operatorname{Cost} E E_{s, m, h}$ & Cost or benefit of electric energy transaction $(€)$ \\
\hline$\lambda_{s, p, m, h}$ & Auxiliary continuous variable for the piecewise linear functions \\
\hline \multicolumn{2}{|l|}{ Free Variables } \\
\hline vGridEnTrans $s_{s, c, m, h}$ & Energy transaction to the grid in each node (MWh) \\
\hline$v$ Electric Cost $t_{s, m, h}$ & Cost or benefit of electric energy transaction $(€)$ \\
\hline$v \operatorname{Cost} E E$ & Total electric energy cost for the considered district $(€)$ \\
\hline$v \operatorname{CostPowE}$ & Total electric power cost for the considered district $(€)$ \\
\hline$v$ CostET & Total thermal energy cost for the considered district $(€)$ \\
\hline
\end{tabular}


C. Calvillo, A. Sánchez, J. Villar, F. Martín. Optimal planning and operation of aggregated distributed energy resources with market participation. Applied Energy. vol. 182, pp. 340-357, November 2016. [Online: August 2016] JCR impact factor: 7.182 (2016)

\begin{tabular}{|c|}
\hline$v \operatorname{CostPowT}$ \\
\hline$v \operatorname{Cost} P V$ \\
\hline$v$ CostBat \\
\hline$v \operatorname{CostHP}$ \\
\hline$v O M P V$ \\
\hline vOMHP \\
\hline$v \operatorname{CostDR}$ \\
\hline$v_{\text {OriginalDemand }}, h$ \\
\hline$\nu$ PriceOriginal ${ }_{m, h}$ \\
\hline$v$ PriceNew $w_{m, h}$ \\
\hline vAvgPriceOriginal \\
\hline$v$ EnergyOriginal $_{m, h}$ \\
\hline$v$ EnergyNew $_{m, h}$ \\
\hline vTotalCostBaseCase \\
\hline$v$ TotalCostNew \\
\hline$v$ CostClientSmallestDistrict \\
\hline$v$ CostClientNewDistrict \\
\hline vWaveragePriceOriginal \\
\hline vWaveragePriceNew \\
\hline vSystemEnergyOriginal $m, h$ \\
\hline vSystemEnergyNew $w_{m, h}$ \\
\hline
\end{tabular}

\section{Binary Variables}

$\chi_{s, s e g, m, h}$
Total thermal power cost for the considered district $(€)$

Total PV investment costs $(€)$

Total battery investment costs $(€)$

Total heat pump investment costs $(€)$

Total PV operation and maintenance costs $(€)$

Total HP operation and maintenance costs $(€)$

Total considered costs for demand response equipment $(€)$

Original electric demand of the considered district (MWh)

Original market electricity price $(€ / \mathrm{MWh})$

New market electricity price (€/MWh)

Original average market electricity price $(€ / \mathrm{MWh})$

Original energy transactions from the district (No DER) (MWh)

New energy transactions from the district (with DER) (MWh)

Total costs at the end of the study for the base case (No DER) ( $€$ )

New total costs at the end of the study for the districts (with DER) ( $€$ )

Total costs per client at the smallest considered district $(€)$

Total costs per client at all other considered districts $(€)$

Energy weighted original average system price (€/MWh)

Energy weighted new average system price (€/MWh)

Original energy of the Spanish electric system (MWh)

New energy (after the DER penetration) of the Spanish electric system (MWh)

Auxiliary binary variable for the piecewise linear functions

\section{Introduction}

Distributed Energy Resources (DER) appear as a group of tools that facilitate the integration of renewable energy while mitigating the challenges of intermittency and the lack of dispatchability of such sources [1]. DER systems include generation, energy storage, and demand response schemes.

Many examples in the literature suggest that these systems can be beneficial for most stakeholders in the energy system [2], especially when aggregated [3]. It is important to remark that most DER owners (also known as producer-consumers or "prosumers" [4]) don't have enough size to participate directly in energy markets (due to the existing entry barriers, [5]), and thus the importance of the aggregator to manage all the DER systems and interact with the market [3], [6]. 
C. Calvillo, A. Sánchez, J. Villar, F. Martín. Optimal planning and operation of aggregated distributed energy resources with market participation. Applied Energy. vol. 182, pp. 340-357, November 2016. [Online: August 2016] JCR impact factor: 7.182 (2016)

This aggregation of distributed energy resources can be done in a variety of ways, such as Virtual Power Plants (VPP, composed by several microgenerators, loads and flexible storage capacities not necessarily geographically close to each other [7]), Microgrids (similar to VPPs, with the difference that loads and resources are geographically concentrated, such as in residential districts or university campus, and can operate connected and/or isolated from the grid [48]) or mobile storage/loads in the form of electrical vehicles (EV) fleets. In addition, the participation in the market of this aggregated resources can be modelled following price-taker or price-maker approaches. Under a price-taker approach, the market participant is considered unable to significantly affect the market price by changing its cleared energy or its offering strategy, and corresponds normally to small players. Computations for this participants can assume constant market prices independently of their strategy. In the price-maker approach it is considered that the market participant affects the market price by clearing more or less energy or by changing its offering strategy, and computation must take into account this impact on the price [16].

Some representative examples of research works found in the literature, focusing in aggregation of resources with market participation have been summarized in Table 1. It is important to remark that, in this paper, the aggregator is the agent (physical or not) responsible of managing a set of resources, such as a microgrid, a VPP, an EV fleet or just a group of clients, and could be a retailer, a distribution company, or another market participant. Regulatory particularities of such agents have not been addressed here as they fall outside the scope of this paper.

Table 1

Summary of resource aggregation models with market participation.

\begin{tabular}{c|cccccc} 
Reference & $\begin{array}{c}\text { Type of } \\
\text { aggregation }\end{array}$ & Methodology & $\begin{array}{c}\text { Market } \\
\text { participation }\end{array}$ & $\begin{array}{c}\text { Time } \\
\text { scope }\end{array}$ & focus & Approach \\
\hline$[7]$ & VPP & Stochastic MILP & $\begin{array}{c}\text { Day-ahead } \\
\text { and balancing }\end{array}$ & Short-term & Operation & Price-taker \\
& & & Bilateral & Short-term & Operation & Price-taker \\
{$[8]$} & VPP & MILP & contracts & & Price-taker \\
{$[9]$} & VPP & Montecarlo & Balancing & Short-term & Operation & Pron \\
{$[11]$} & Microgrid & Stochastic MILP & Day-ahead & Short-term & Operation & Price-taker
\end{tabular}


C. Calvillo, A. Sánchez, J. Villar, F. Martín. Optimal planning and operation of aggregated distributed energy resources with market participation. Applied Energy. vol. 182, pp. 340-357, November 2016. [Online: August 2016] JCR impact factor: 7.182 (2016)

\begin{tabular}{l|cccccc}
{$[12]$} & $\begin{array}{c}\text { Microgrid, } \\
\text { EV fleet }\end{array}$ & MILP & Day-ahead & Short-term & Operation & Price-taker \\
{$[13]$} & $\begin{array}{c}\text { Microgrid } \\
\text { Microgrid, }\end{array}$ & MPEC & Balancing & Short-term & Operation & Price-taker \\
{$[14]$} & Tabu search & $\begin{array}{c}\text { Internal } \\
\text { market }\end{array}$ & Short-term & Operation & Price-maker \\
& EV fleet & & Internal & Medium- & & \\
{$[49]$} & Microgrid & MCP & market & term & Planning & Price-maker \\
& Retailer & Genetic & Day-ahead & Short-term & Operation & Price-taker \\
{$[16]$} & loads $)$ & algorithm & and intradays & & & \\
& VPP & NLP & Day-ahead & Short-term & Operation & Price-taker \\
{$[36]$} & VPP & MILP & Day-ahead & Short-term & Operation & Price-maker \\
{$[38]$} & VPP & EPEC & Day-ahead & Short-term & Operation & Price-maker \\
{$[37]$} & Microgrid & LP & N/A & Long-term & Planning & Price-taker \\
{$[35]$} & & & & &
\end{tabular}

An example of a VPP model has been proposed in [7], composed by a two-stage stochastic mixedinteger linear programming model which maximizes the virtual power plant expected profit. This model buys and sells energy from the day-ahead and balancing markets. Similarly, a mixed-integer linear programming model based on robust optimization approach has been proposed in [8] to reduce the risk of not meeting bilaterally contracted energies by a VPP. Conversely, authors in [9] analyze the integration of wind power into the grid by using VPPs, focusing on balancing wind power and energy costs with micro-CHP (combined heat and power systems). Lastly, in [10] the technical and economic aspects of VPPs have been reviewed and its competitiveness in a deregulated market environment has been studied.

Examples of Microgrids managed by aggregators can be found in [11] and [12]. The former proposes a stochastic problem for the optimal operation of a microgrid, implementing several DER systems, with the objective of placing optimal hourly bids in the day-ahead market. The latter presents an aggregator that manages distributed generation and a smart parking lot with $200 \mathrm{EVs}$. The main objective of the model they propose was to compute the optimal day-ahead energy schedule of the microgrid and the EVs that minimizes the operation costs. Both models follow a price-taker approach and involve only the operation of DER systems in the short term (1 day). Another example can be found in [13], where an aggregator works with a wind power producer, 
C. Calvillo, A. Sánchez, J. Villar, F. Martín. Optimal planning and operation of aggregated distributed energy resources with market participation. Applied Energy. vol. 182, pp. 340-357, November 2016. [Online: August 2016] JCR impact factor: 7.182 (2016)

and uses demand-response to cope with the power production uncertainty and market violations. To solve this problem, single-level mathematical program with equilibrium constraints (MPEC) is proposed.

A different methodology has been developed in [14], where an aggregator manages loads, distributed generation (DG) and EVs of a district with the particularity that the customers have elastic demand curves as linear functions of the electricity price, leading to an additional internal market between the aggregator and its prosumers. Tabu search [15] has been used to solve the proposed non-linear problem, and the scope of the model is to find the optimal scheduling for the external day-ahead energy markets, given the energy usage expected from the internal market clearing. Similarly, a planning and operation of isolated microgrids is proposed in [49], where an internal market is implemented and the market price is solved using a mix complementarity problem (MCP). Another more general example of bidding strategies can be found in [16] where an aggregator manages its energy offers for the day-ahead market, and also for the six intraday markets in the Spanish energy system. The optimization problem has been solved with a genetic algorithm.

In [36], pumped storage hydro has been used to balance wind power generation in the electricity markets, following both price-taker and price-maker approaches, using a non-linear optimization problem. Authors remark that the operation of the considered systems and the participation in the market change considerably due to the approach taken. Other price-maker approaches can be found in [37] and [38], where energy storage technologies have been used for energy arbitrage, the latter also analyzing the particular strategic behaviors of different types of storage systems. Operation and planning of DER systems under different low-voltage network topologies have been analyzed in [35], following a price-taker approach.

Despite the amount of research available about DER aggregation, as it can be clearly seen in Table 1, most work focus on operation only in the short term, from those considering investment planning, very few consider direct transactions with the market in their planning process, and most of them follow a price-taker approach (the problem formulation might be inexact and might provide misleading results). In addition, stochastic optimization models are rare in this kind of application. Hence, the work proposed in this paper intends to fulfil this gap in the literature 
C. Calvillo, A. Sánchez, J. Villar, F. Martín. Optimal planning and operation of aggregated distributed energy resources with market participation. Applied Energy. vol. 182, pp. 340-357, November 2016. [Online: August 2016] JCR impact factor: 7.182 (2016)

proposing a stochastic optimal planning problem of aggregated DER systems with market participation, following a price-maker approach. To the best of the authors' knowledge, such a model has not been proposed in the literature.

The goal of this paper is to propose a price-maker model for DER systems planning in a district (which can be considered either a microgrid or a VPP) operated by an aggregator that participates in the electricity market. The importance of following a price-maker approach in comparison with a price-taker one is analyzed by modeling the impact of the aggregator's actions on the final electricity price. The optimal planning and operation of DER systems considering market uncertainty, the benefits of their aggregation and the assessment of when a price-maker approach should be followed depending on the amount of aggregated resources are some of the main contributions of this paper. It is important to remark that the proposed methodology does not imply any market modification but only provides a better way to compute the impact of DER systems in the final market price, in comparison with the simpler but less realistic price-taker models.

Two programming problems have been proposed to analyze different approaches in the planning stage: a deterministic Price-maker model, and a stochastic Price-maker model to cope with market uncertainty. The impact of the aggregator on the market has been simulated by clearing the aggregator's energy (to sell or to buy) against a set of residual demand curves (RDC) [16] representing the different scenarios analyzed. Solar photovoltaic panels (PV) and air-source heat pumps (HP) have been selected as representative DG technologies for electric and thermal energy production. For the energy storage, conventional battery systems have been considered.

The rest of the paper is organized as follows. In Section 2, a brief description of the optimization model can be found, while in Section 3 its full mathematical formulation has been presented. In Section 4 the case studies considered in this research and the DER implementation scenarios have been described. Results of the case studies and a discussion of their implications have been provided in Section 5. Concluding remarks can be found in Section 6.

\section{Model description}

The base scheme considered in this study is composed by an aggregator that manages a large number of residential clients (implementing DER systems). This aggregator also has a connection 
C. Calvillo, A. Sánchez, J. Villar, F. Martín. Optimal planning and operation of aggregated distributed energy resources with market participation. Applied Energy. vol. 182, pp. 340-357, November 2016. [Online: August 2016] JCR impact factor: 7.182 (2016)

to the electricity market, making possible to sell and buy energy in the day-ahead market session. The ownership of the distributed energy resources has been attributed to be on the residential clients, and the aggregators act like a distribution-level retailer (market participator) that sends dynamic price signals to its clients to manage their consumption behavior and resources. Reliability issues and the economic interactions client-retailer (business models) have not been addressed in this study, as they fall outside the scope of the paper. In addition, it is considered that the contractual relationship between the generic aggregator or retailer and the clients, the profit sharing among the participants, and the possible business models that could be established, do not really impact on the optimal management of DER systems. Also, unbalance issues have not been taken into account, as the real time operation (where the unbalances occur) has not been considered.

The optimization model proposed is a mixed-integer linear programming one, and its objective is to maximize the profit of an aggregator that has to decide the investments and the operation of a set of distributed energy resources. Model inputs include the costs and performance values (e.g., electric efficiency, thermal efficiency, power rating, and losses) of the DER systems considered, geolocation characteristics (sun irradiation), energy requirements (consumer electric and thermal demand curves) and each scenario has been modeled with a set of market residual demand curves. These curves change depending on the type of model selected (stochastic or deterministic) and the case study considered. Outputs comprise optimal investments planning (installed capacities) and operation of DER systems, with the corresponding grid energy buying and selling schedules, and the energy market price. For the sake of simplicity, a year has been modeled with one representative day per month, for a total of $288 \mathrm{~h}$. The distributed energy resources considered are: distributed generation (PV, Heat pump), storage systems (water tanks and batteries), and demand response schemes. Since the time scope of this model is the long-term (20 years), uncertainties in renewable energy production have not been taken into account, as it is considered that average values can deliver sensible results (given the long-term nature of the problem). Moreover, in order to model renewable production uncertainties, extra scenarios (e.g. with low, medium and high production) and/or larger time periods (e.g. considering one full year instead of 12 representative days) have to be included, incrementing considerably the computation time. 
C. Calvillo, A. Sánchez, J. Villar, F. Martín. Optimal planning and operation of aggregated distributed energy resources with market participation. Applied Energy. vol. 182, pp. 340-357, November 2016. [Online: August 2016] JCR impact factor: 7.182 (2016)

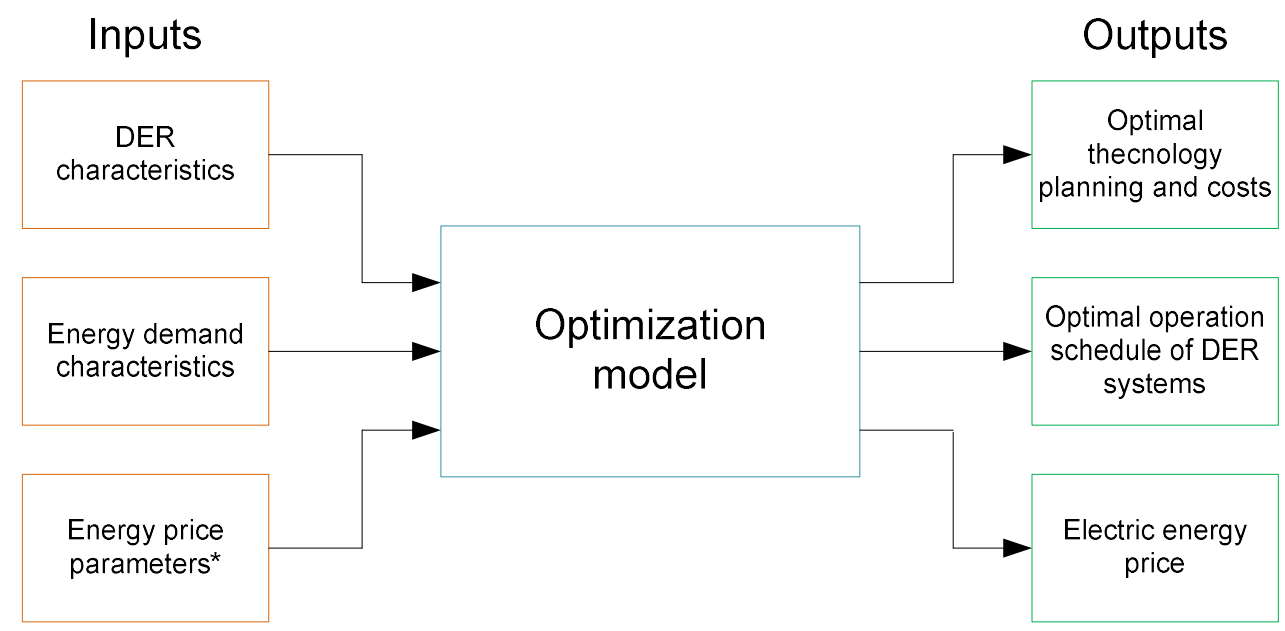

* these parameters change depending to the kind of model

Fig. 1. Block diagram of the proposed optimization models.

The Spanish electricity market is composed of the wholesale market, the intraday markets (a time scheme of such sessions can be found in [16]), the balancing market and the ancillary service markets. Due to the long-term scope of this study, and considering that most energy is traded in the day-ahead session, the proposed model considers only the participation in the day-ahead market.

Greenhouse gas emissions are not taken into account in this study, as the computation of such reductions is a complex problem, that falls outside of the scope of this paper and deserves a deeper analysis. Indeed, to analyze the effect of price changes in the reduction of emissions, it seems necessary to develop a detailed unit commitment model where the commitment and production of the thermal power plants given the new operation of DER clients can be used to quantify the new emissions. An example of such type of analysis can be found in [56], where a full unit commitment model of the Spanish system is used for this purpose.

\section{Mathematical formulation}

This section describes the two stage stochastic optimization model to find the optimal scaling and operation of DER systems (PV systems, HP systems, batteries, and demand response schemes) to 
C. Calvillo, A. Sánchez, J. Villar, F. Martín. Optimal planning and operation of aggregated distributed energy resources with market participation. Applied Energy. vol. 182, pp. 340-357, November 2016. [Online: August 2016] JCR impact factor: 7.182 (2016)

be installed in a set of buildings connected by a distribution network. It has been considered that the buildings do not have any preexisting DER installation. A typical year's operation characterized by 12 days, each one representing a month of the year, is replicated for the total length of the study. For the sake of brevity, only the stochastic price-maker problem has been fully described, as the deterministic price-maker changes only in the number of scenarios (one in that case).

In the following formulation a $v$ has been added at the beginning of the variable names, a $p$ for the parameters, and the sets have been included as sub-indexes at the end of the parameter or variable names.

\subsection{Objective function}

The proposed objective function maximizes the benefits of all the prosumers (producerconsumers) in the network in an aggregated manner; this has been done by reducing the equivalent energy costs. Indeed, the objective function is composed by the energy incomes and costs, and the costs of the DER systems, considering both equipment investments and maintenance. It is calculated as:

$$
\begin{gathered}
\max \{-v \operatorname{Cost} E E-v \operatorname{CostPowE}-v \operatorname{CostPV}-v O M P V-v \operatorname{Cos} t B a t-v \operatorname{Cost} E V-v \operatorname{Cos} t H P \\
-v O M H P-v \operatorname{CostET}-v \operatorname{CostPowT}-v \operatorname{CostDR}\}
\end{gathered}
$$

Where:

$$
\begin{aligned}
& v \operatorname{Cost} E=\sum_{y}\left(p \operatorname{Cost} E_{y}\right. \\
& * \sum_{s} \sum_{m}\left(\text { daysMonth }_{m}\right. \\
& \left.\left.* \sum_{h}\left(\operatorname{prrobs}_{s, m, h} *\left(v \text { ElectricCost }_{s, m, h}+v{\operatorname{GridCost} E E_{s, m, h}}\right)\right)\right)\right) \\
& v \operatorname{CostPo}-w E=\sum_{y}\left(p \operatorname{Cost} E_{y} * \text { pFixEpow } * \sum_{s} \sum_{c}\left(\text { probAvg }_{s} * v \text { PowElect }_{s, c}\right)\right)
\end{aligned}
$$


C. Calvillo, A. Sánchez, J. Villar, F. Martín. Optimal planning and operation of aggregated distributed energy resources with market participation. Applied Energy. vol. 182, pp. 340-357, November 2016. [Online: August 2016] JCR impact factor: 7.182 (2016)

$$
\begin{aligned}
& v \operatorname{CostPV}=\sum_{c}\left(p \operatorname{CostPV} * v \text { PowerP } V_{c}\right) \\
& v O M P V=\sum_{C}\left(\text { pOMfixPV } * v \text { PowerP } V_{c} * \text { LLifespan }\right) \\
& v \text { CostBat }=\sum_{c}\left(\text { CostBat } * \text { BatCapacity }{ }_{c}\right) \\
& v \operatorname{CostET}=\sum_{y}\left(p \operatorname{CostT}_{y} * \sum_{s} \sum_{c} \sum_{m}\left(\text { probAvg }_{s} * \text { pDaysMont }_{m} * v \text { BoughtEnergy }_{s, c, m}\right)\right) \\
& \text { vCostPowT }=\text { pLifespan } * \text { pNumHouses } * \text { pHouseMultiplier } * \text { pFixTpow } \\
& v \text { CostHP }=\sum_{c}\left(p \operatorname{CostHP} * v \text { PowerHP } P_{c}\right) \\
& \text { vOMHP }=\sum_{C}\left(\text { pOMfixHP } * \text { vPower } H P_{c} * \text { pLifespan }\right) \\
& v \text { CostDR }=\text { pNumHouses } * \text { pHouseMultiplier } * p \text { DRequipCost }
\end{aligned}
$$

From the previous equations, it can be seen that (2) sum up the electricity costs/benefits produced by the transactions with the grid. The variable vElectricCost is positive when energy is bought from the grid and it is negative when energy is sold (the negative costs represents profit). Equation (3) is used to compute the cost of the contracted electricity power amount and (7), (8) relate to the thermal energy costs and access tariffs, respectively. Equations (4), (6), (9) and (11) describe the distributed resources equipment costs, whereas equations (5) and (10) compute the total operation and maintenance costs. All the parameters used in these and the rest of the equations in this section have been described in section 4 .

This objective function has been formulated considering the total lifespan of the project set to 20 years (considering this is the lifespan of HP and PV systems [39], [40]) with battery replacements every 8 years [19] (when they have been included in the DER planning outcome of the optimization problem), and investments, if any, take place at the beginning of the study period.

\subsection{State-of-Charge constraints:}

The following constraints describe the behavior of the battery storage systems, affecting mainly the state-of-charge (SOC) which is the rate of stored energy with respect to the battery maximum capacity, typically expressed as a percentage (similar to a fuel gauge). These constraints limit the 
C. Calvillo, A. Sánchez, J. Villar, F. Martín. Optimal planning and operation of aggregated distributed energy resources with market participation. Applied Energy. vol. 182, pp. 340-357, November 2016. [Online: August 2016] JCR impact factor: 7.182 (2016)

charge to the maximum capacity and the discharge to the current energy level. Current SOC has been computed from the previous SOC by adding and subtracting the energy charged and discharged.

$$
\begin{aligned}
& v S O C_{s, c, m=1, h=0}=0 \\
& v S O C_{s, c, m, h=0}=v S O C_{s, c, m-1, h=24} \forall m \in[2,12] \\
& v S O C_{s, c, m, h=1}=v S O C_{s, c, m, h=24} \forall m \in[2,11] \\
& v_{S O C_{s, c, m, h}}=\text { vBatCapacity }{ }_{c} \\
& v S O C_{s, c, m, h}=v S O C_{s, c, m, h-1}-v D i s B a t_{s, c, m, h}+v \text { ChBat }_{s, c, m, h} \\
& v \text { DisBat }_{s, c, m, h} \leq v S O C_{s, c, m, h-1} \\
& v \text { ChBat }_{s, c, m, h} \leq v \text { BatCapacity } y_{c}-v S O C_{s, c, m, h-1}
\end{aligned}
$$

\subsection{Demand Response constraints:}

The following equations model load shifting under a demand response scheme. Equation (19) makes the daily total of the new managed demand to be the same as the original demand (no elasticity). Equation (20) balances the demand shift per hour and accounts for the energy increased and decreased at that hour. The maximum amount of load that can be shifted per day has been limited by the parameter $p$ DemandShift, as shown in (21), i.e. the amount of increments of demand (and consequently demand decrements in other hours) must be lower or equal to a percentage of the daily total demand.

$$
\begin{aligned}
& \sum_{h} \text { vDemandNew }_{s, c, m, h}=\sum_{h} \text { pDemandElec } \\
& c, m, h \\
& \text { DDemandNew } w_{s, c, m, h}+v \text { DecDemand } d_{s, c, m, h}=\text { pDemandElec }_{c, m, h}+\text { vIncDemand }_{s, c, m, h} \\
& \sum_{h} \text { vIncDemand }_{s, c, m, h} \leq \text { DDemandShift } * \sum_{h} \text { pDemandElec } c_{c, m, h}
\end{aligned}
$$

\subsection{Energy Production constraints:}

The PV system production is modelled with (22) (taken from [50]), which is an approximation of PV power generation extensively used for DER system planning models, as in [49], [35] and [25]. The variable $v$ ProdPV refers to the electric energy produced by the PV system, where DNI stands for Direct Normal Irradiance $(\mathrm{W} / \mathrm{m} 2)$, which is the energy provided by the sun at a specified 
C. Calvillo, A. Sánchez, J. Villar, F. Martín. Optimal planning and operation of aggregated distributed energy resources with market participation. Applied Energy. vol. 182, pp. 340-357, November 2016. [Online: August 2016] JCR impact factor: 7.182 (2016)

location. The $v$ Power $P V$ refers to the selected size of the system. Lastly, $G$ is the global irradiation received on a horizontal plane $(\mathrm{G}=1000 \mathrm{~W} / \mathrm{m} 2)$. Note that the time step of all the considered data is 1 hour. Equation (23) presents the approximated thermal generation equation for an air-source heat pump. It is important to remark that thermal generation has been considered to have a greater output than its actual production as it has been compared with the cost of producing the same amount of energy with a conventional gas boiler at $80 \%$ efficiency. Also, note that more detailed models for both PV and HP production are available, normally used for real-time operation studies (including generation and demand uncertainty), but such real-time issues fall outside the scope of this paper.

$$
\begin{aligned}
& \begin{aligned}
& \operatorname{PProdPV}_{c, m, h}= \frac{p D N I_{m, h} * v \text { PowerP }_{c}}{G} *(1-\text { pLossesPV }) \\
& \begin{aligned}
& \text { vBoughtEnergy } T_{s, c, m} \\
&=p \text { DemandTherm } \\
& c, m
\end{aligned} \\
&-\sum_{h}\left(v \text { ElecHPinput }_{s, c, m, h} * \text { pCOP } *(1-\text { pLossesHP })\right) / 0.8
\end{aligned}
\end{aligned}
$$

Constraint (24) limits the electric production of the heat pump below the nominal installed power. Continuing with HP operation, (25) is intended to avoid thermal generation only in hours that is less likely to be used, making it produce at least $30 \%$ of total demand in the afternoon-evening hours.

$$
\begin{aligned}
& \text { vElecHPinput }_{s, c, m, h} \leq v \text { PowerHP } \\
& \sum_{h}\left(\text { vElecHPinput }_{s, c, m, h} * \text { pCOP }\right) * \frac{(1-\text { pLossesHP })}{0.8} \geq 0.3 * \text { pDemandTherm }_{c, m} \forall h \in[13,20]
\end{aligned}
$$

The following equation has been used to calculate the required contracted electric power given the DG production.

$$
\text { vPowElect }_{s, c} \geq \text { vGridEnerTrans }{ }_{s, c, m, h}
$$


C. Calvillo, A. Sánchez, J. Villar, F. Martín. Optimal planning and operation of aggregated distributed energy resources with market participation. Applied Energy. vol. 182, pp. 340-357, November 2016. [Online: August 2016] JCR impact factor: 7.182 (2016)

\subsection{Balance Equation:}

Equation (27) is required to balance the total energy consumption and production at every period, where all the energy that enters each node is positive and the energy that leaves the node is negative.

$$
\begin{aligned}
& \text { vGridEnTrans } s_{s, c, m, h} \\
& =v \text { DemandNew }_{s, c, m, h}-v \operatorname{ProdPV}_{c, m, h}-v \operatorname{DisBat}_{s, c, m, h} * \text { pEffBat } \\
& +\left(\frac{v \text { ChBat }_{s, c, m, h}}{p E f f B a t}\right)+v \text { TransEnergy }_{s, c, m, h}-v \operatorname{RecEnergy}_{s, c, m, h} \\
& +v \text { ElecHPinput }_{s, c, m, h}
\end{aligned}
$$

\subsection{Electricity cost constraints:}

The constraints in this and the next subsection have been used to calculate the electric energy costs from the market price, using a piecewise linear approximation. First, (28) has been used to separate the positive and negative parts of the energy transactions with the grid. This is to pay the equivalent share of network usage when buying energy, considering that this cost is to be paid by the buyer and not the seller of energy, as formulated in (29).

$$
\begin{aligned}
& \text { vGridEnTotalPos } s_{s, m, h}-\text { vGridEnTotalNeg } g_{s, m, h}=\sum_{c} \text { vGridEnTrans }_{s, c, m, h} \\
& \text { vGridCostE } E_{s, m, h}=\text { GridTariffEE } * v_{\text {GridEnTotalPos }}, m, h
\end{aligned}
$$

\subsection{Piecewise linear function constraints:}

The piecewise linear functions have been modeled as described in [20]. The piecewise function is characterized by the points connecting the linear segments. In this paper, 23 points have been used to model the 22 considered segments for the energy cost curve approximation. The detailed process for the piecewise linear function approximation can be found in section 4.2. 
C. Calvillo, A. Sánchez, J. Villar, F. Martín. Optimal planning and operation of aggregated distributed energy resources with market participation. Applied Energy. vol. 182, pp. 340-357, November 2016. [Online: August 2016] JCR impact factor: 7.182 (2016)

The positive auxiliary variable $\lambda$ has been used in (30) to compute the electricity cost as a linear combination of energy cost values of the considered points (pYparameter) previously described. Similarly, the energy value of the piecewise linear function is translated to a linear combination of the $p$ Xparameter values, as shown in (31).

$$
\begin{aligned}
& \text { vElectricCost }_{s, m, h}=\sum_{p}\left(\lambda_{s, p, m, h} * \text { pYparameter }_{s, p, m, h}\right) \\
& \text { vGridEnTotalPos }_{s, m, h}-\text { vGridEnTotalNe }_{s, m, h}=\sum_{p}\left(\lambda_{s, p, m, h} * \text { pXparameter }_{s, p, m, h}\right)
\end{aligned}
$$

It is important to remark that the sum of all $\lambda$ variables cannot be greater than 1 , as shown in (32). However, to avoid being in more than one segment of the piecewise function, the binary variable $\chi$ is used (also, the sum of all $\chi$ cannot be greater than one, and thus, only the $\chi$ of one of the segments will be equal to 1 and the rest will be 0 , as shown in (36)). This binary variable makes the optimization problem a mixed integer programming one. The constraints (33) - (35) complete the piecewise linear function formulation, allowing the $\lambda$ variables to be greater than 0 if the binary variable is 1 (the active segment of the piecewise linear function), and to be zero otherwise. A more detailed explanation of this piecewise approximation can be found in [20].

$$
\begin{aligned}
& \sum_{p} \lambda_{s, p, m, h}=1 \\
& \lambda_{s, p=1, m, h} \leq \chi_{s, s e g=1, m, h} \\
& \lambda_{s, s e g, m, h} \leq \chi_{s, s e g-1, m, h}+\chi_{s, s e g, m, h} \forall s e g \in[2,21] \\
& \lambda_{s, p=23, m, h} \leq \chi_{s, \text { seg }=22, m, h} \\
& \sum_{\text {seg }} \chi_{s, \text { seg }, m, h}=1
\end{aligned}
$$

\section{Scenarios and Case Studies}

\subsection{Case study description and parameters}

Three case studies with different DER planning approaches have been analyzed:

- Case study A: Price-maker with deterministic approach (average scenario). 
C. Calvillo, A. Sánchez, J. Villar, F. Martín. Optimal planning and operation of aggregated distributed energy resources with market participation. Applied Energy. vol. 182, pp. 340-357, November 2016. [Online: August 2016] JCR impact factor: 7.182 (2016)

- Case study B: Price-maker with deterministic approach (most likely scenario).

- Case study C: Price-maker with stochastic approach.

For all cases different sizes of aggregated districts have been analyzed. To adequately simulate a district different types of domestic energy users have been considered. According to [21] residential clients in Spain can be classified in four kinds depending on the age of the head of the family (HF) and/or the presence of young children in the household: head of the family with less than 35 years, head of the family between 35 and 65 years old, head of the family with more than 65 years, and family with children younger than 14 years old. Fig. 2 and Fig. 3 show the typical electricity demand curves for every type of client in summer and winter seasons, calculated as an average of historical data [21].

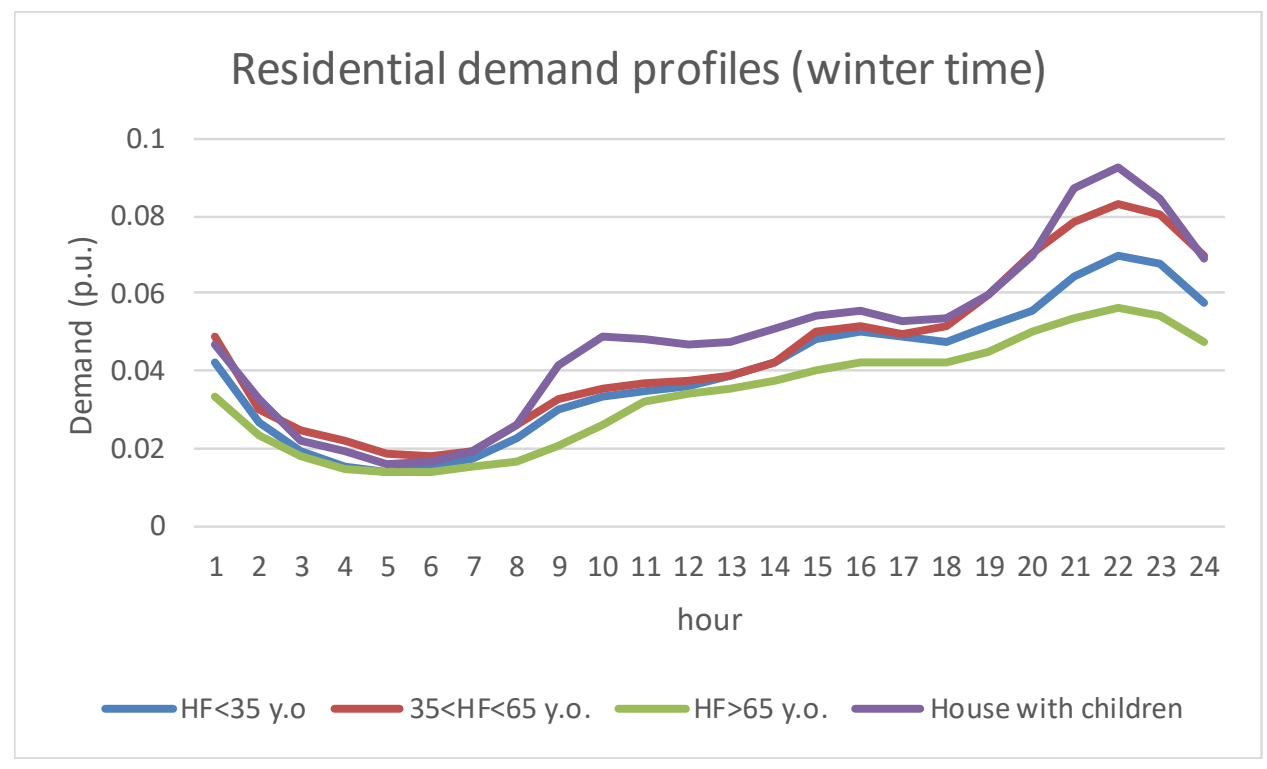

Fig. 2. Normalized residential demand curves for winter time (4 types of users). 
C. Calvillo, A. Sánchez, J. Villar, F. Martín. Optimal planning and operation of aggregated distributed energy resources with market participation. Applied Energy. vol. 182, pp. 340-357, November 2016. [Online: August 2016] JCR impact factor: 7.182 (2016)

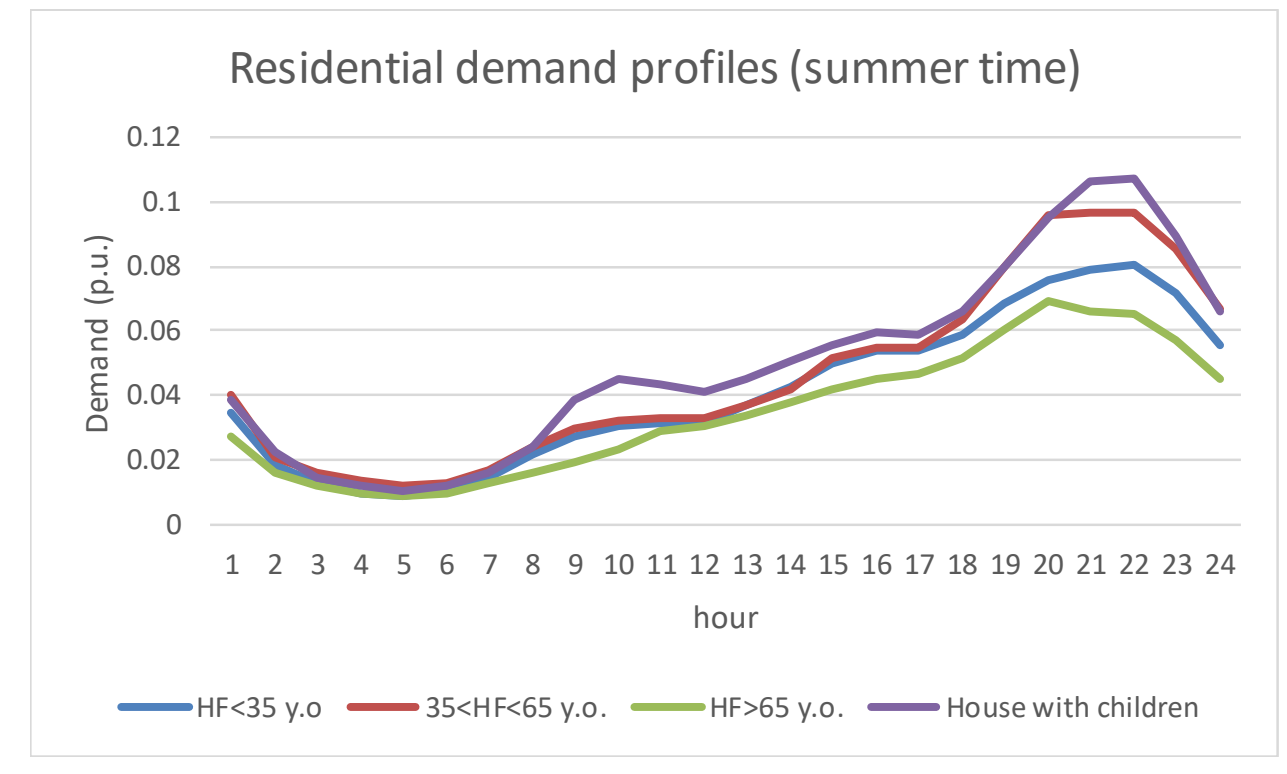

Fig. 3. Normalized residential demand curves for summer time (4 types of users).

Table 2 summarizes the annual energy consumption per client type and the difference with respect to the Spanish residential average value per household. The monthly energy demand throughout a year is represented in Fig. 4 [21].

Table 2

Total annual energy consumption per client type.

\begin{tabular}{c|ccc} 
Type of client & $\begin{array}{l}\text { Comparison with } \\
\text { average value }\end{array}$ & $\begin{array}{l}\text { Annual } \\
\mathbf{( k W h}\end{array}$ & $\begin{array}{l}\text { Thermal } \\
\text { (kWh) }\end{array}$ \\
\hline HF $<35$ y.o. & $-5 \%$ & 6054.9747 & 3507.0613 \\
$35 \leq \mathrm{HF}<65$ y.o. & $8 \%$ & 6871.7046 & 3980.1140 \\
HF $\geq 65$ y.o. & $-19 \%$ & 5174.3962 & 2997.0274 \\
House with & $16 \%$ & 7422.3987 & 4299.0778 \\
children & & &
\end{tabular}


C. Calvillo, A. Sánchez, J. Villar, F. Martín. Optimal planning and operation of aggregated distributed energy resources with market participation. Applied Energy. vol. 182, pp. 340-357, November 2016. [Online: August 2016] JCR impact factor: 7.182 (2016)

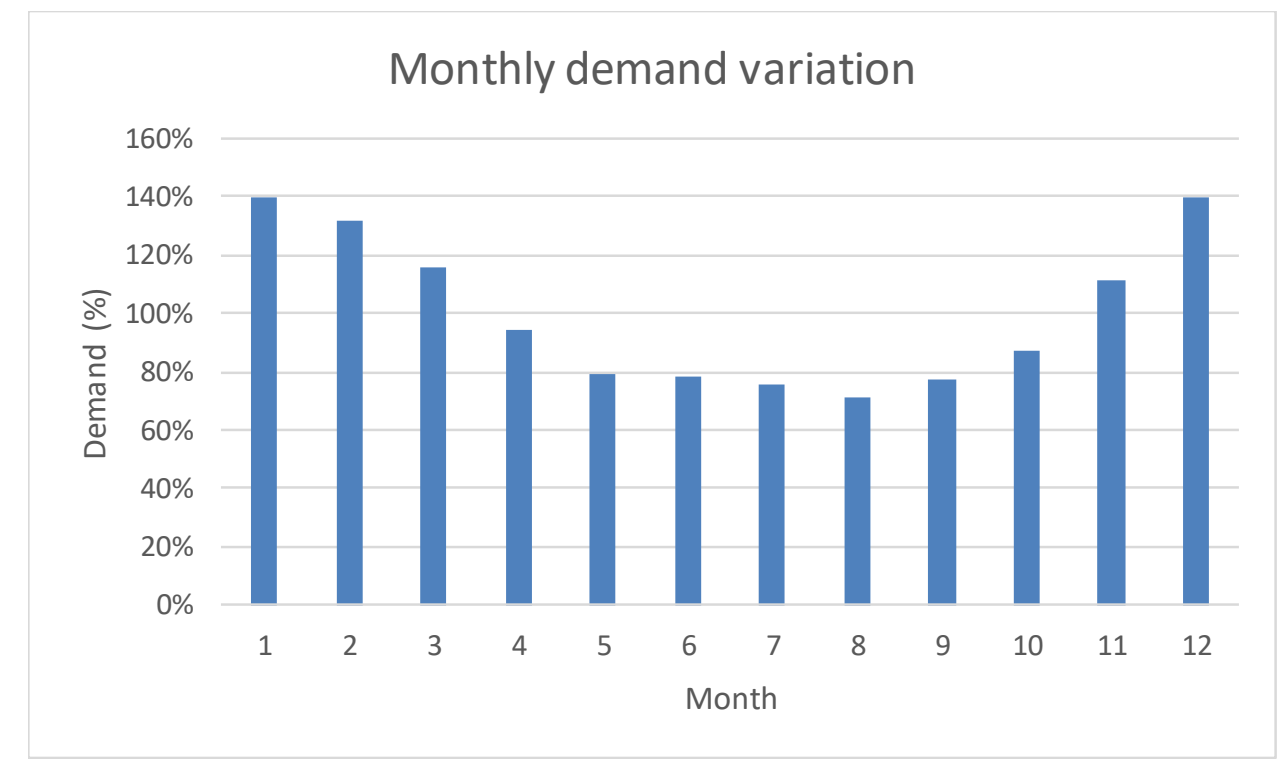

Fig. 4. Monthly demand variation for the residential electric sector in Spain.

For thermal energy, it has been considered that most residential customers have a hot water tank or other means of thermal storage, so there is no an hourly demand curve. However, constraint (25) has been added to have a minimum thermal production during peak hours, to avoid concentrating all the thermal energy in a few off-peak hours when is less likely to be used. Moreover, it has been assumed that the total thermal use follows the same monthly percentage pattern of Fig. 4.

In this study, the solar characteristics of Madrid, Spain, have been considered, and solar production has been calculated with hourly DNI data from [22]. Other required parameters have been summarized in Tables 3 and 4. The former, with data taken from [23], presents the access tariffs to be paid by each household (due to the contracted power), the thermal energy cost (in the form of natural gas) and the electric energy cost for network operation and maintenance, cost to be paid in addition to the cost of the energy bought from the market (according to [24], the network cost and taxes represents about $60 \%$ of the tariff). The electricity price will be the resulting price of the market (an output of the model), and it is not included here. Note that these prices are at the wholesale level and not at the consumer level. Table 4 shows the costs and performance parameters (including losses) of the considered distributed energy resources (taken from [42], [43] and [44], 
C. Calvillo, A. Sánchez, J. Villar, F. Martín. Optimal planning and operation of aggregated distributed energy resources with market participation. Applied Energy. vol. 182, pp. 340-357, November 2016. [Online: August 2016] JCR impact factor: 7.182 (2016)

losses from [22], [49] and [51]). Battery charge/discharge efficiency has been set to 95\% [42]. The coefficient of performance (COP) of the heat pump has been assumed in 2.5 units, considered as an average COP throughout the year [41]. Indeed, the COP of HP system varies constantly as a function of the difference between indoor-outdoor temperatures, and thus, the approximation used is expected to have an error in real-time operation (in summer time the COP is likely to be smaller, and in winter time the COP is likely to be larger). However, given the long-term scope of this study, it is considered that the average value used deliver sensible results. Other works with similar COP range can be found in [49], [54] and [55].

The pDemandShift parameter has been calculated considering the appliances that can be more easily shifted in time. According to [26], the washing machine, dryer and dish washer represent the $13.3 \%$ of the total electric consumption of a typical Spanish household; hence, the pDemandShift parameter has been established to a maximum $13 \%$ of total daily load. A fixed cost pDRequipCost of $250 € /$ house represents the cost of the control devices needed for demand response [45].

Table 3

Power tariffs and thermal energy pricing.

\begin{tabular}{l|c} 
Access tariffs (Power) & Price \\
\hline Electric (Annual) & $38043(€ / \mathrm{MW})$ \\
Thermal (Annual) & $106.08(€ / \mathrm{Client})$ \\
\hline Natural gas tariff: & $74.3(€ / \mathrm{MWh})$ \\
\hline Network costs share: & $44.02(€ / \mathrm{MWh})$ \\
\hline
\end{tabular}

Table 4

Technology costs and expected energy losses.

\begin{tabular}{l|lll} 
Technology & Inst. Cost $(\boldsymbol{\epsilon} / \mathbf{W})$ & O\&Mfix $(\boldsymbol{\epsilon} / \mathbf{k W})$ & Losses (\%) \\
\hline PV & 2.15 & 30.93 & 24 (electric) \\
HP $(\mathrm{COP}=2.5)$ & 2.94 & 100.1 & 15 (thermal)
\end{tabular}


C. Calvillo, A. Sánchez, J. Villar, F. Martín. Optimal planning and operation of aggregated distributed energy resources with market participation. Applied Energy. vol. 182, pp. 340-357, November 2016. [Online: August 2016] JCR impact factor: 7.182 (2016)

\begin{tabular}{l|lll} 
Battery & $0.36(€ / \mathrm{Wh})$ & - & 10 (electric)
\end{tabular}

\subsection{Scenario description}

The scenarios proposed consist of residual demand curves (RDC) used by the aggregator to assess its impact on the market price when selling or buying energy, and thus, the aggregator optimizes its energy transactions for each hour. In a simple way, a residual demand curve of a market participant is a function that relates the market clearing price to the quantity sold by the participant in that hour. It is obtained by adding up the demand curves of the competitors and subtracting their supply curves, or equivalently, by removing the market participant own aggregated supply curve from the total aggregated residual demand curve of the market [32]. It is a well-known approach for representing the competitors' behavior, and is commonly used by market participants to formulate effective oligopolistic strategies [33]. The RDC for the representative days used to model year 2013 have been computed from real market data taken from [17] and [18], and used in all residual demand curve scenarios. In the deterministic problem 288 representative residual demand curves have been computed, corresponding to one representative curve per hour, 24 hours per day and 12 representative days for the year. For the stochastic case, three sets of 288 curves have been created (i.e. 3 scenarios per hour). Then, an energy cost curve has been computed for every residual demand curve considered and a piecewise linear approximation has been carried out to implement them in the optimization model, [27]. It is important to remark that both the calculation of the energy cost curve and the use of a piecewise linear approximation have been implemented to avoid the non-linearity of this kind of model (the minimization of the energy costs depends on the energy transaction and the energy price, which is also function of the energy, making it a non-linear problem) and having a mixed-integer linear programming one.

This process can be described as follows:

1. For a particular month, all the residual demand curves of the same hour, but of different days of the same month, have been grouped. For instance, for January at 10 h00 there are 31 curves. In the deterministic cases, there is no distinction between working days and holidays; however, the stochastic scenarios create different groups of days. 
C. Calvillo, A. Sánchez, J. Villar, F. Martín. Optimal planning and operation of aggregated distributed energy resources with market participation. Applied Energy. vol. 182, pp. 340-357, November 2016. [Online: August 2016] JCR impact factor: 7.182 (2016)

2. Using the K-means clustering algorithm implemented in MATLAB [28], a representative curve has been created ( 3 representatives for the stochastic case) for each hour of each representative day of each month. This clustering methodology has been used effectively to create RDC scenarios, as shown in [47].

3. With the representative demand curve, the energy cost curve has been computed by multiplying all the energy values by its corresponding price. This preprocessing has been developed to avoid nonlinearities in the programming problem, as proposed in [27].

4. The piecewise linear approximation has been carried out using the Recursive DouglasPeucker Polyline Simplification algorithm, implemented in MATLAB [29]. The tolerance parameter has been fine-tuned to create 22 segments for the piecewise linear function, putting especial emphasis in the area where the clearing is more likely to occur. This procedure is repeated for all the 288 hours considered representative of the whole year.

\subsubsection{Average scenario for the deterministic model (Case study A).}

For this case study, the process described above has been applied and an average representative has been taken from all the residual demand curves of a particular hour in that month. Fig. 5 shows the curves for all the month of January at 10h, and their representative curve (dashed red line). 
C. Calvillo, A. Sánchez, J. Villar, F. Martín. Optimal planning and operation of aggregated distributed energy resources with market participation. Applied Energy. vol. 182, pp. 340-357, November 2016. [Online: August 2016] JCR impact factor: 7.182 (2016)

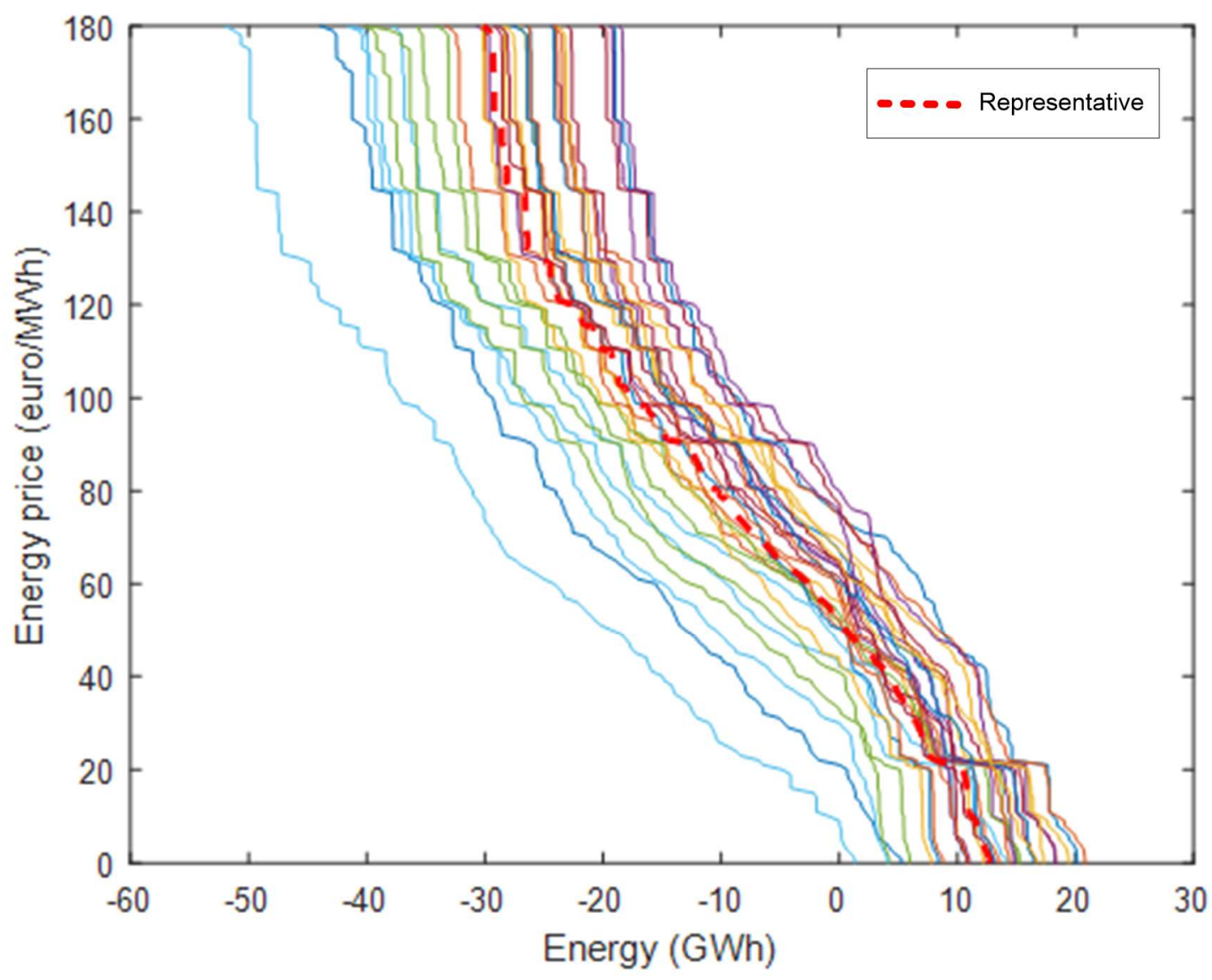

Fig. 5. Residual demand curves of all days of January at hour 10 and the computed representative curve.

For all the representatives obtained with the abovementioned process, the energy cost curve has been computed, by multiplying the energy quantity times its price, and the piecewise linear approximation has been applied. Fig. 6 shows an example of the piecewise linear functions obtained (dashed line in red) for the corresponding energy cost curve (solid line in blue). Positive costs are for buying energy, while negative costs represent profits for selling energy. 
C. Calvillo, A. Sánchez, J. Villar, F. Martín. Optimal planning and operation of aggregated distributed energy resources with market participation. Applied Energy. vol. 182, pp. 340-357, November 2016. [Online: August 2016] JCR impact factor: 7.182 (2016)

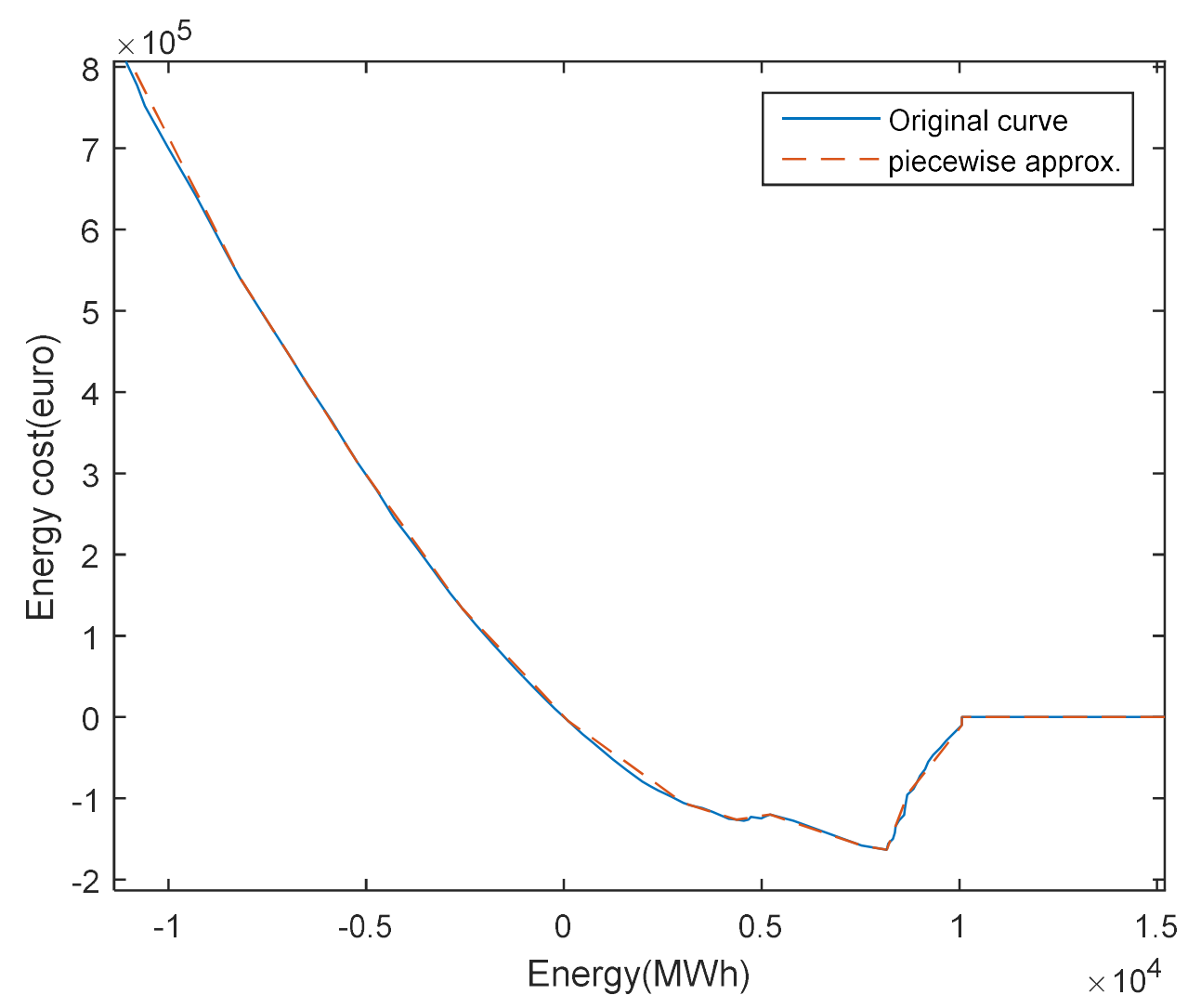

Fig. 6. Piecewise linear approximation of the energy cost curve (Case study A, January 8h00).

\subsubsection{The most likely scenario (Case study B) and three scenarios for the stochastic model (Case study C).}

Case study B has been proposed to analyze the aggregated system with market values that are likely to occur. This approach gives relevant information that might be lost in the average scenario considered previously, as the clustering in a single representative behaves as an average of all the samples, and tends to over-smooth the residual demand curve. Case study $\mathrm{C}$, on the other hand, tries to model the uncertainty of the markets by following a stochastic approach.

For the deterministic model with the most likely scenario and the stochastic one, the same procedure described previously has been carried out, with the only difference that now three representative curves have been created instead of one, and thus 288 sets of three curves have been created. While case $\mathrm{C}$ uses the three curves per hour, case B only uses the one with greater probability corresponding to the representative of the largest cluster. The selection of three 
C. Calvillo, A. Sánchez, J. Villar, F. Martín. Optimal planning and operation of aggregated distributed energy resources with market participation. Applied Energy. vol. 182, pp. 340-357, November 2016. [Online: August 2016] JCR impact factor: 7.182 (2016)

scenarios for the stochastic model has been done, firstly, due to computational constraints as the number of binary variables in the problem make it difficult to solve and time consuming, secondly, because the three scenarios provides good approximation of the reality, according to the silhouette clustering validation method [30]. This method permits to assess how well represented are the residual demand curves by the three representatives created. The results of this test, carried out in MATLAB, gives a Silhouette value of 0.67 , which can be translated to $83.37 \%$ of correctness in the clustering representatives. Note that the silhouette value ranges from -1 to +1 . A high value indicates that the sample is well-matched to its own cluster, and poorly-matched to neighboring clusters (the clusters are different enough). Hence, if most samples have a high silhouette value, then the clustering solution is appropriate [31].

Fig. 7 exemplifies a set of energy cost curves with their corresponding piecewise linear functions approximations. The probability of each scenario has been calculated as the proportion of samples (days) classified in each cluster regarding the total number of samples (number of days in each month) [47]. 
C. Calvillo, A. Sánchez, J. Villar, F. Martín. Optimal planning and operation of aggregated distributed energy resources with market participation. Applied Energy. vol. 182, pp. 340-357, November 2016. [Online: August 2016] JCR impact factor: 7.182 (2016)

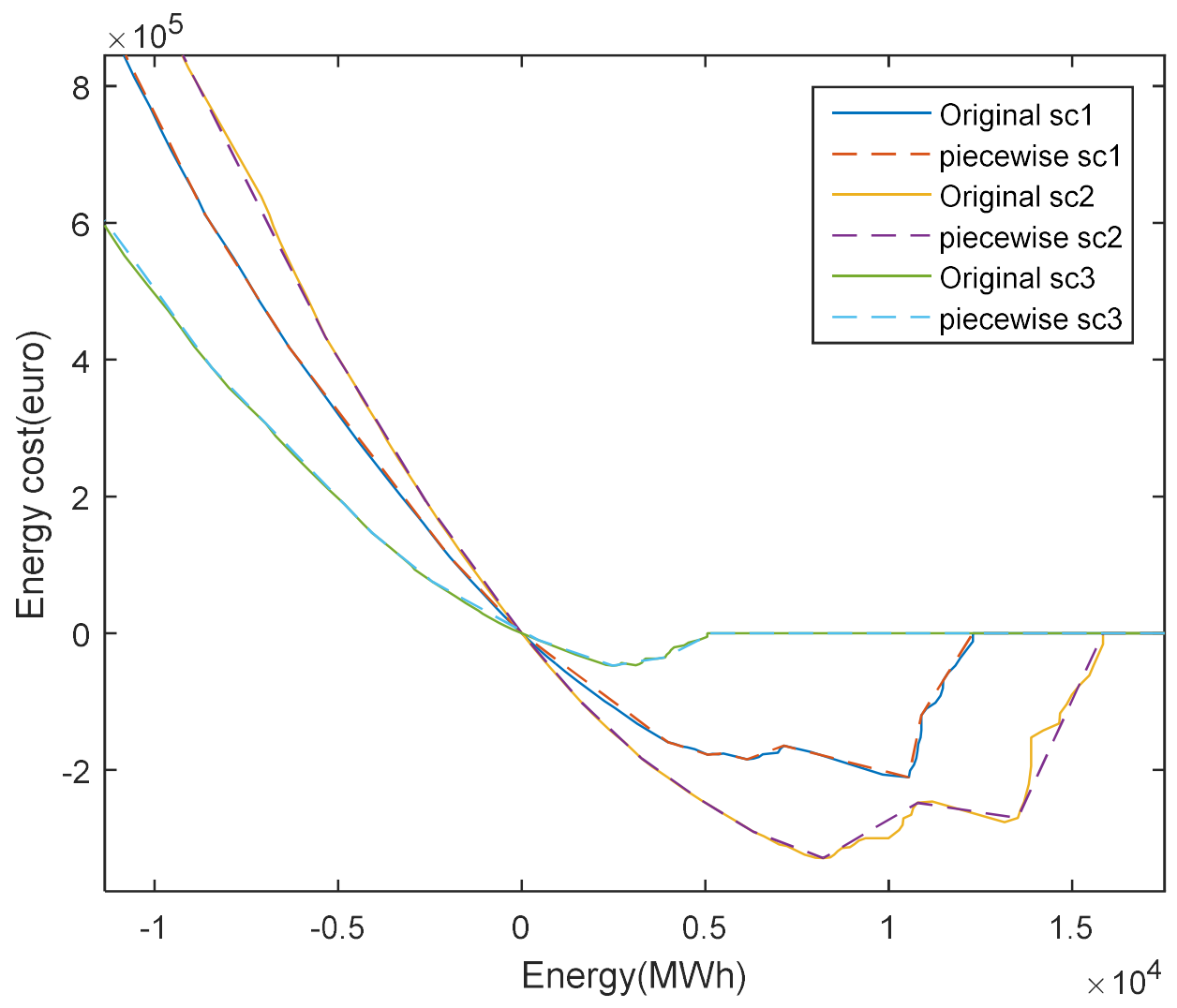

Fig. 7. Piecewise linear approximation of the energy cost curves (Case study B and C, January 10h00).

\subsubsection{Residual demand curve adjustment for different loads.}

The residual demand curves obtained from [17] and [18] include the total generation and demand of the Spanish system, and the resulting market price (the price of the energy at that particular hour) falls at energy $=0 \mathrm{MWh}$ (equilibrium between generation and demand of all the system). Therefore, the proposed aggregator needs to take out the original load of the considered district from such curves before placing offers in the electricity market. Otherwise it will be like if the considered aggregated clients have been added to the system, artificially increasing the total system demand.

To correct this problem, a similar methodology as in [33] and [34] has been applied, so the original unmanaged load of the considered group of aggregated clients is removed from the residual demand curves, by shifting the curves to the left in the same number of units of energy as the demand removed. Fig. 8, shows an example of such curve shift, where the blue solid line 
C. Calvillo, A. Sánchez, J. Villar, F. Martín. Optimal planning and operation of aggregated distributed energy resources with market participation. Applied Energy. vol. 182, pp. 340-357, November 2016. [Online: August 2016] JCR impact factor: 7.182 (2016)

represents the original curve and the red curve is the adjusted one. In Fig. 9, the original (blue) and adjusted (red) energy cost curves are shown. It can be seen that removing load (moving the residual demand curve to the left) makes the price to decrease (the crossing with zero energy falls at a lower price), which implies lower energy costs when the energy is bought from the grid (red curve in Fig. 9). If there is no energy management and the same amount of energy is bought from the grid (as the original case), the red line will be shifted back to where the blue line is, getting the original market price for that hour.

Note that this curve adjustment not only makes the energy price lower for buying energy, but it also produces lower income for selling energy (the curve is shifted further to the left, reducing more the market price), affecting the strategies taken by the aggregator.

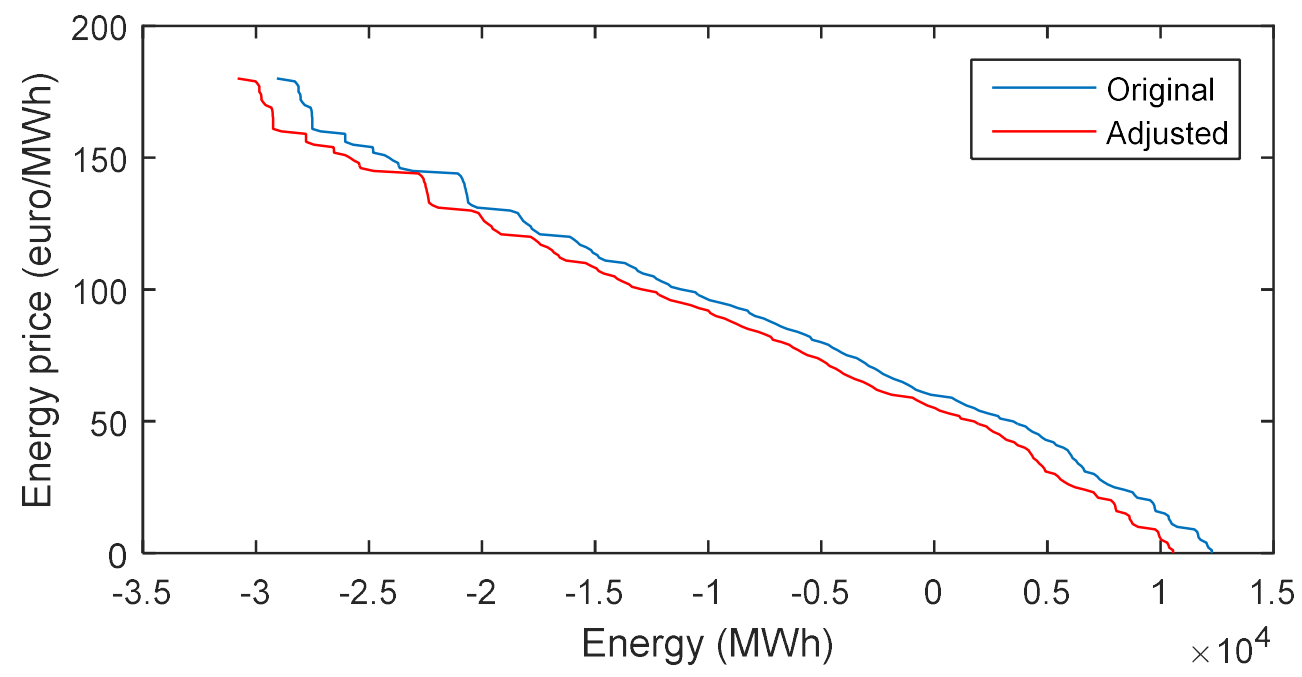

Fig. 8. Adjusted residual demand curve (January 10h00). 
C. Calvillo, A. Sánchez, J. Villar, F. Martín. Optimal planning and operation of aggregated distributed energy resources with market participation. Applied Energy. vol. 182, pp. 340-357, November 2016. [Online: August 2016] JCR impact factor: 7.182 (2016)

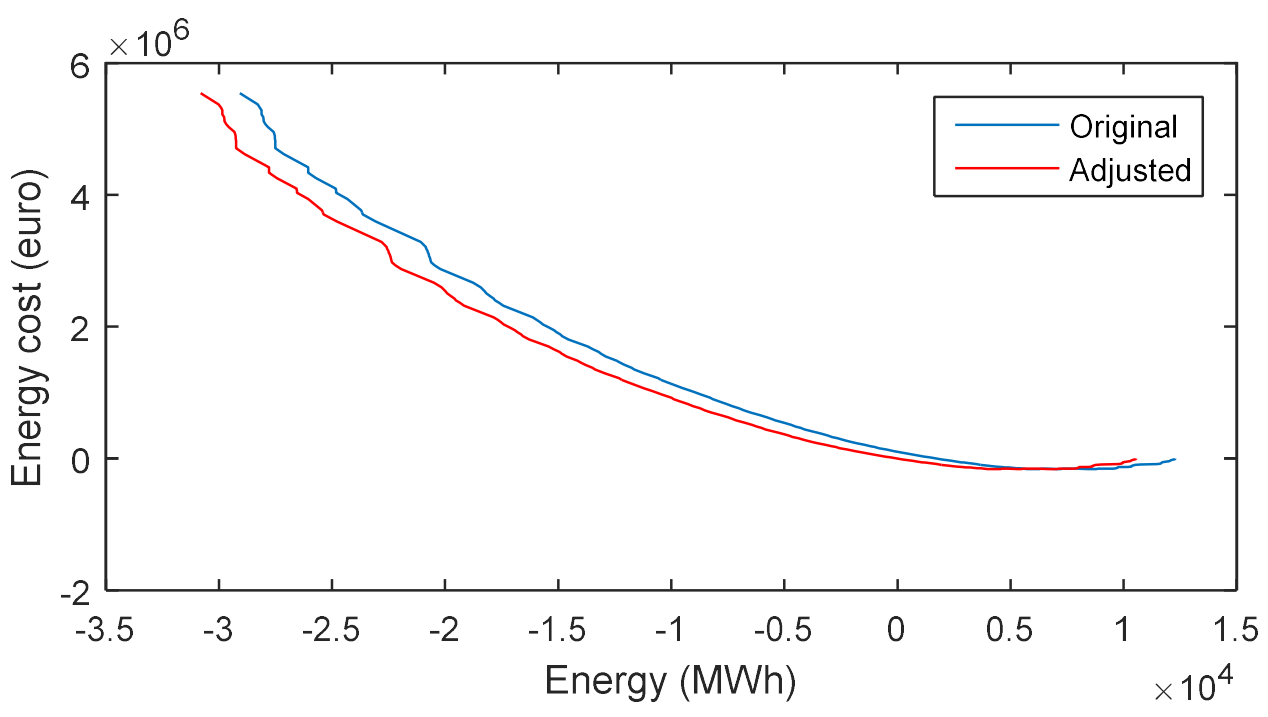

Fig. 9. Adjusted energy cost curve (January 10h00).

\section{Results and discussion}

This section presents the results of the optimization models proposed, and the effect of the amount of aggregated resources is analyzed. For the sake of comparison, the results of the three case studies have been grouped and discussed in section 5.2. It is important to remark that, as network constraints have not been included, the optimal DER planning solely depends on the type of client, and not on its location in the network [35].

\subsection{Aggregated system behavior for all study cases}

The first model implemented is the deterministic one that considers the average residual demand curve of each hour of each day (Case study A). Fig. 10 and Fig. 11 show the electric energy transaction from the grid of the considered clients implementing DER systems (net demand from the grid, considering consumption, generation and management of resources) and its effect on electricity prices. For the sake of brevity, only two out of the twelve representative days have been shown (one for winter and one for summer), and three district sizes (which could be considered: small, medium and large). For the winter day, the original energy price (blue line, Fig. 10) has lower prices in the early morning (off-peak time) and higher prices from $16 \mathrm{~h}$ to $24 \mathrm{~h}$ (peak time). 
C. Calvillo, A. Sánchez, J. Villar, F. Martín. Optimal planning and operation of aggregated distributed energy resources with market participation. Applied Energy. vol. 182, pp. 340-357, November 2016. [Online: August 2016] JCR impact factor: 7.182 (2016)

As expected, it can be seen that the energy price changes more for the larger district (red line), and the price barely changes in the smaller district (see Fig. 10, the red line is over the blue line).

a) $\mathbf{4 0}$ thousand houses

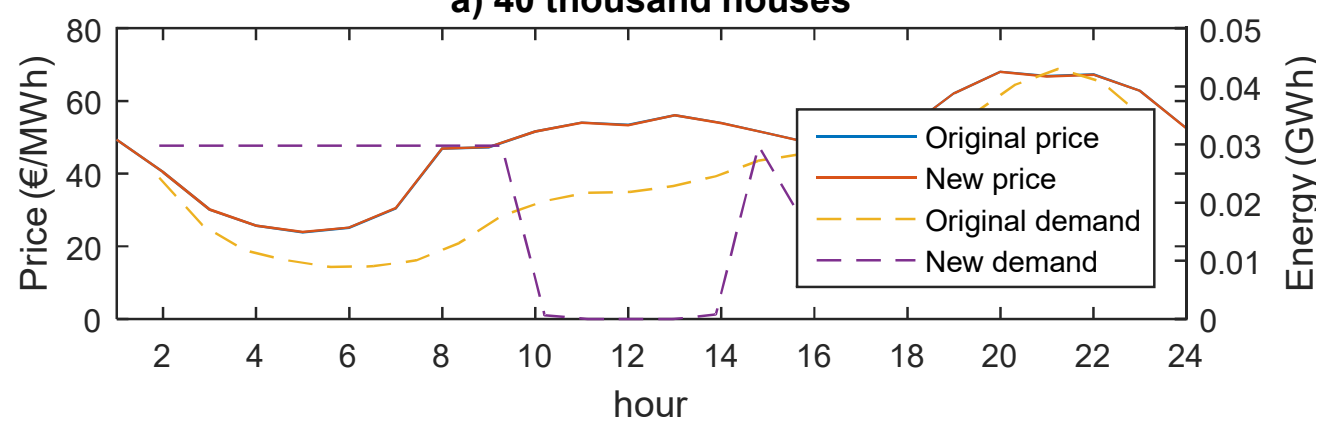

b) 1 million houses

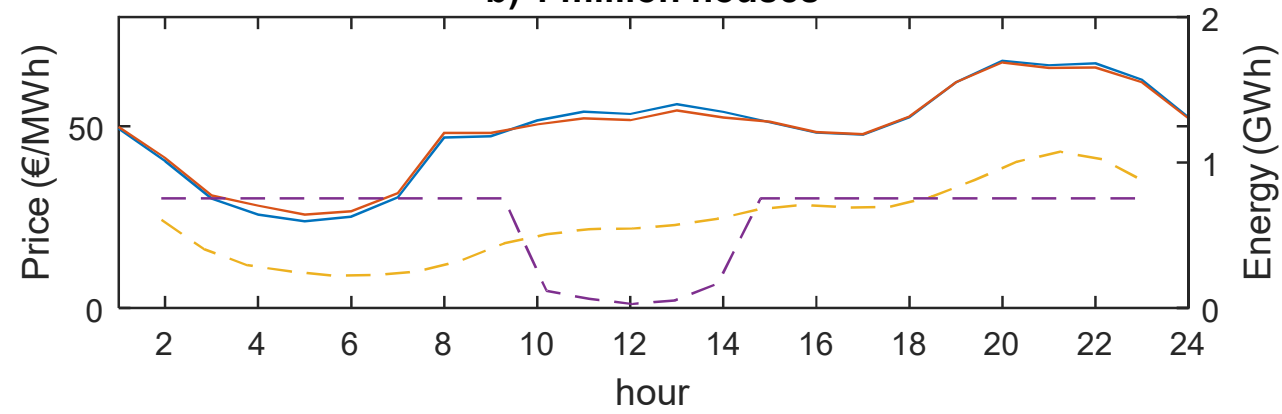

c) 8 million houses

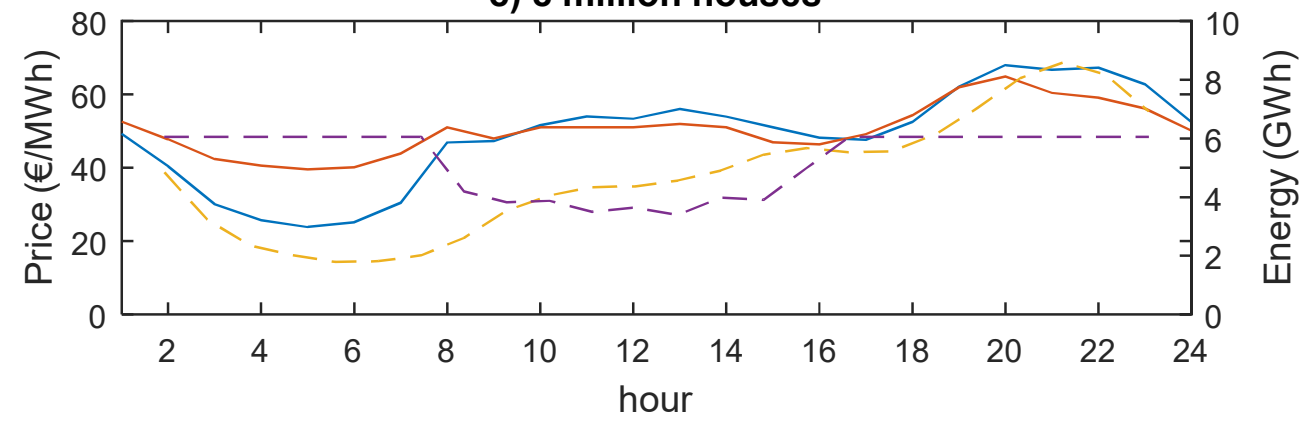

Fig. 10. Aggregator energy transactions and effect on energy price for the representative day of January (Case study A), a) for 40000, b) 1000000 and c) 8000000 houses.

In the representative summer day, the original price curve (blue line, Fig. 11) is flatter than its equivalent at winter. However, the behavior of the aggregator is similar, reducing energy transactions at the middle of the day with the PV production, and shifting load to such hours. The new energy price (red line, Fig. 11) is lower, especially at the sunny hours (mainly $8-18 \mathrm{~h}$ ). 
C. Calvillo, A. Sánchez, J. Villar, F. Martín. Optimal planning and operation of aggregated distributed energy resources with market participation. Applied Energy. vol. 182, pp. 340-357, November 2016. [Online: August 2016] JCR impact factor: 7.182 (2016)

\section{a) 40 thousand houses}

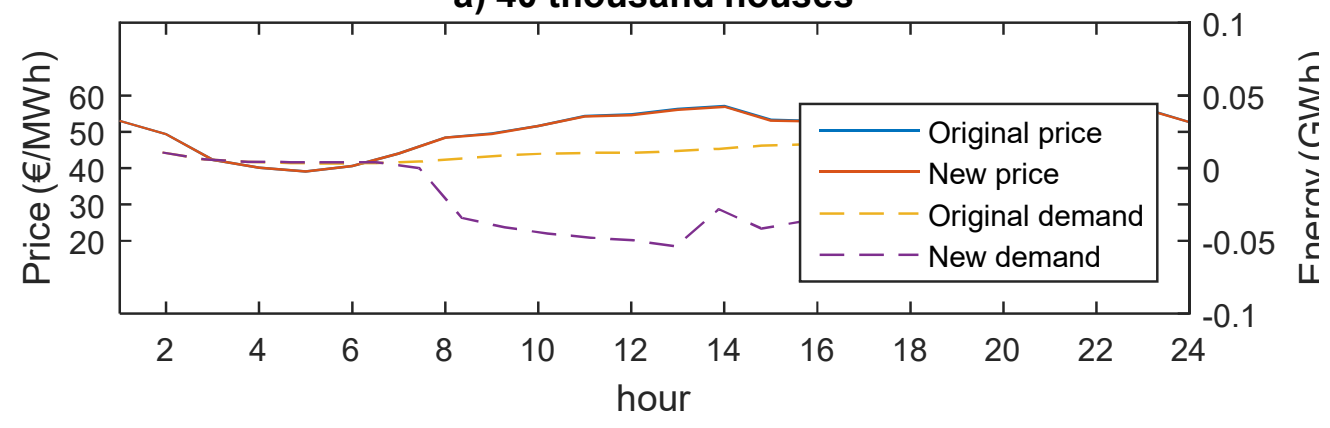

b) 1 million houses

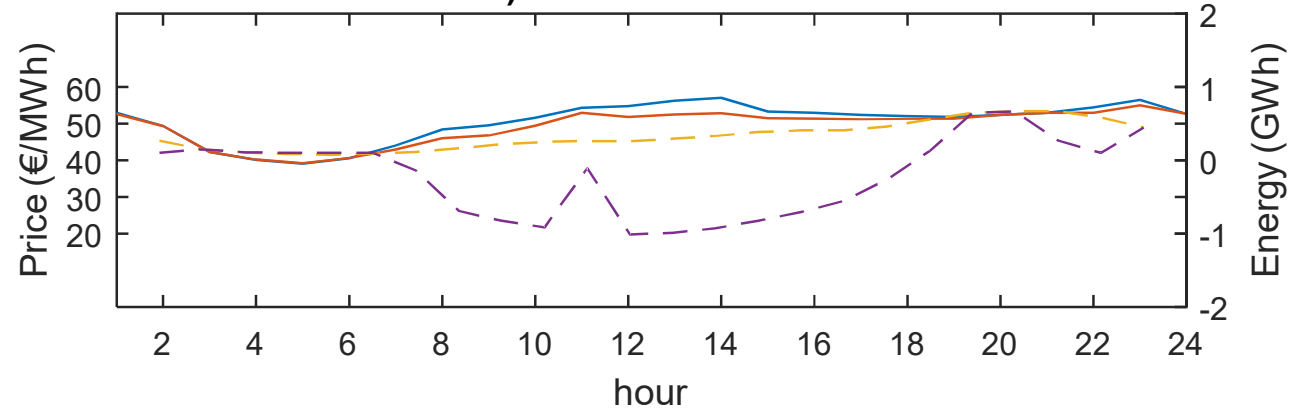

c) 8 million houses

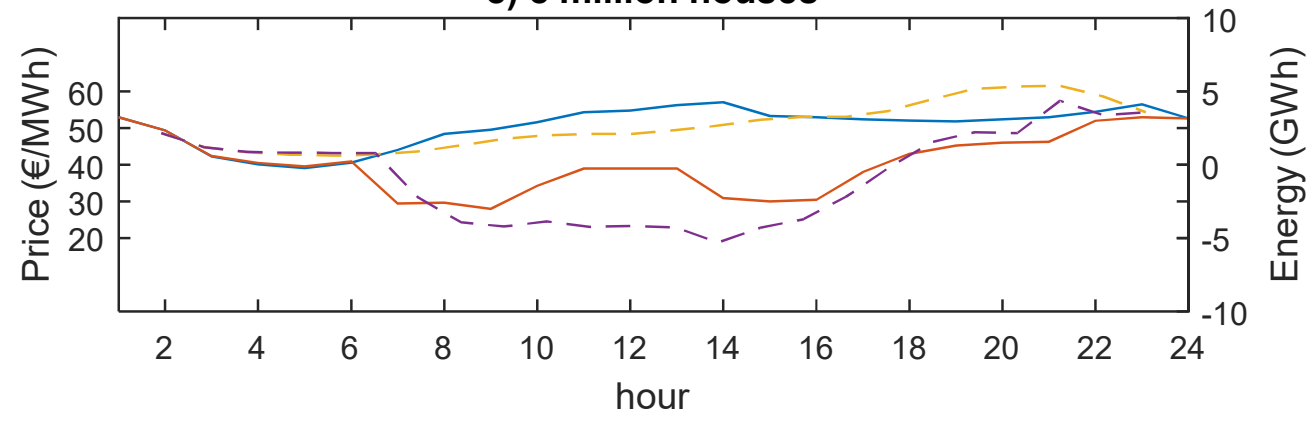

Fig. 11. Aggregator energy transactions and effect on energy price for the representative day of July (Case study A), a) for 40000, b) 1000000 and c) 8000000 houses.

The behavior of the aggregated systems for Case study B is shown in Fig. 12 and Fig. 13. In this case study, it has been used the representative energy cost curve from the largest cluster out of the three computed at each hour.

As it can be seen, the aggregator takes advantage of the larger difference between off-peak and peak time electricity prices $(23-78 € / \mathrm{MWh}$ in Fig. 12, in comparison with $24-68 € / \mathrm{MWh}$ in Fig. 10), promoting more load shifting. Moreover, the price at sunny hours is slightly higher in 
C. Calvillo, A. Sánchez, J. Villar, F. Martín. Optimal planning and operation of aggregated distributed energy resources with market participation. Applied Energy. vol. 182, pp. 340-357, November 2016. [Online: August 2016] JCR impact factor: 7.182 (2016)

this case study (over $60 € / \mathrm{MWh}$ at $14 \mathrm{~h}$ in Fig. 13, in comparison with $57 € / \mathrm{MWh}$ at $14 \mathrm{~h}$ in Fig. 11), encouraging the aggregator to sell energy during such hours, especially in summer months as can be seen in Fig. 13.

a) $\mathbf{4 0}$ thousand houses

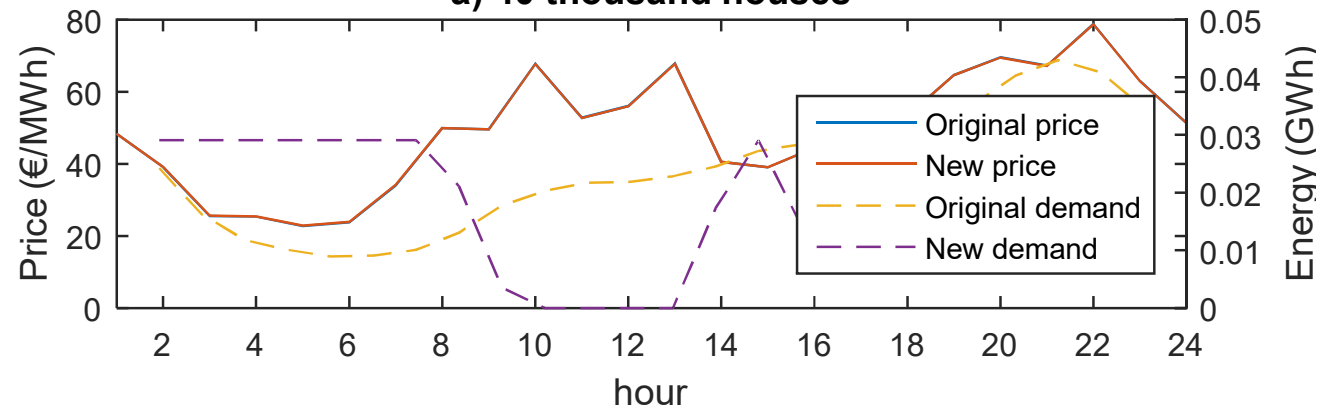

b) 1 million houses

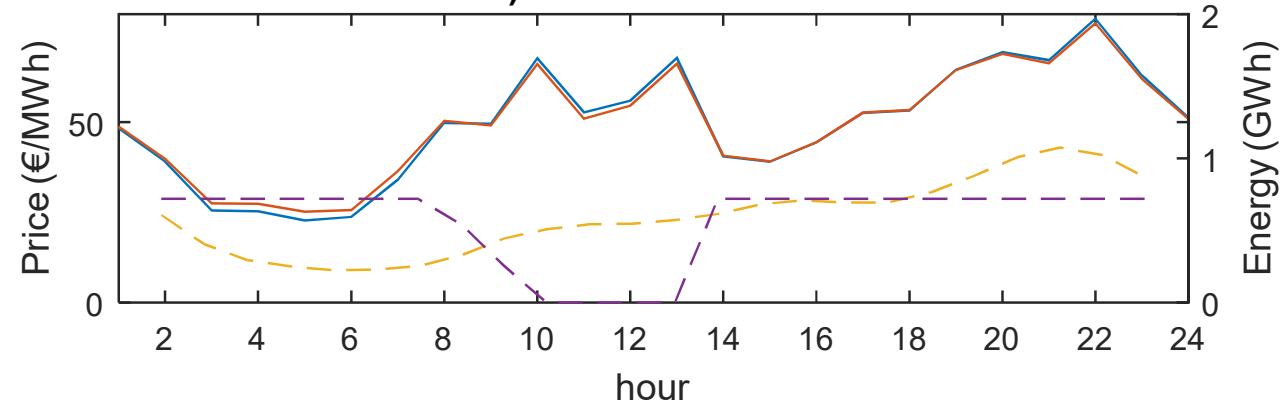

c) 8 million houses

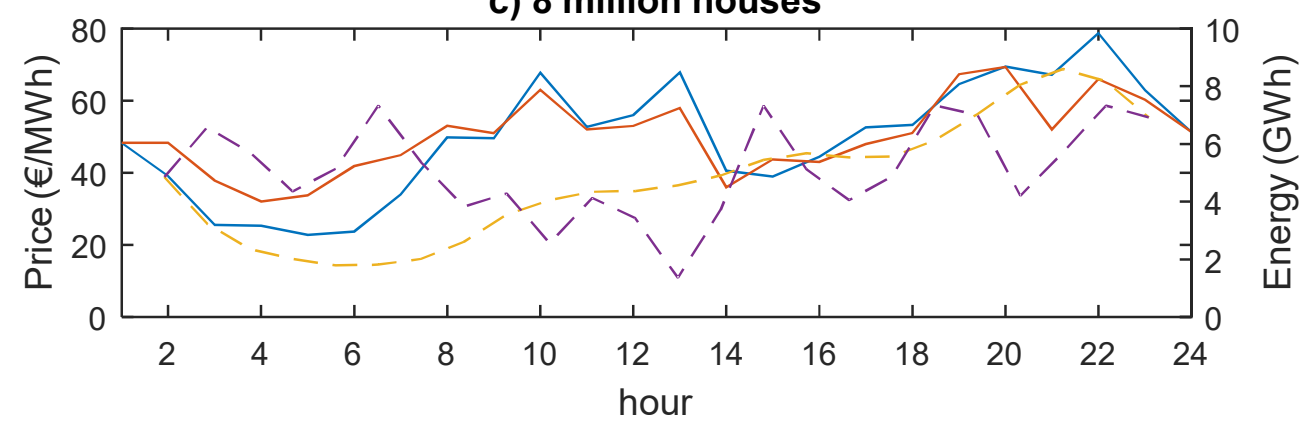

Fig. 12. Aggregator energy transactions and effect on energy price for the representative day of January (Case study B), a) for 40000, b) 1000000 and c) 8000000 houses. 
C. Calvillo, A. Sánchez, J. Villar, F. Martín. Optimal planning and operation of aggregated distributed energy resources with market participation. Applied Energy. vol. 182, pp. 340-357, November 2016. [Online: August 2016] JCR impact factor: 7.182 (2016)

a) $\mathbf{4 0}$ thousand houses

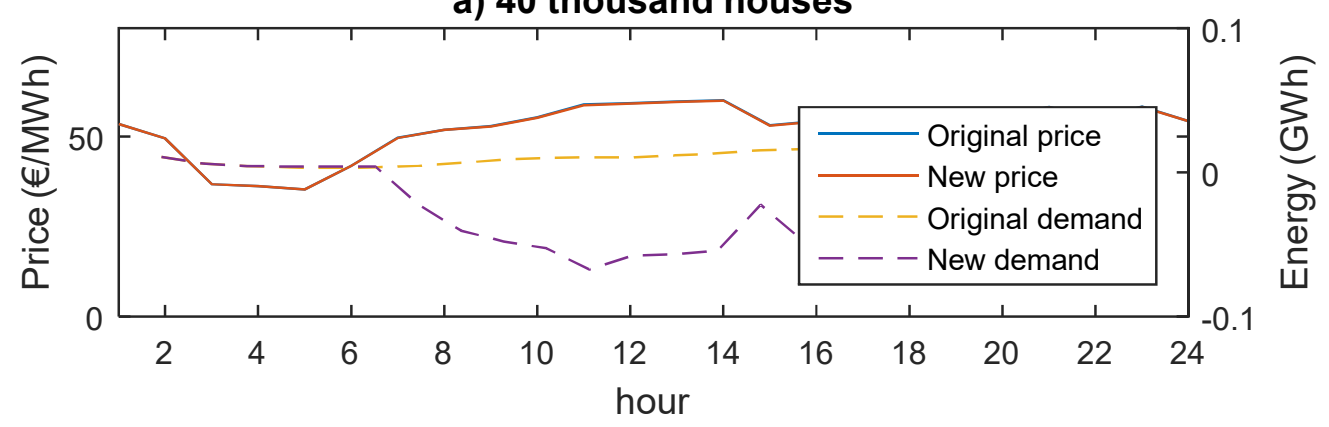

b) 1 million houses

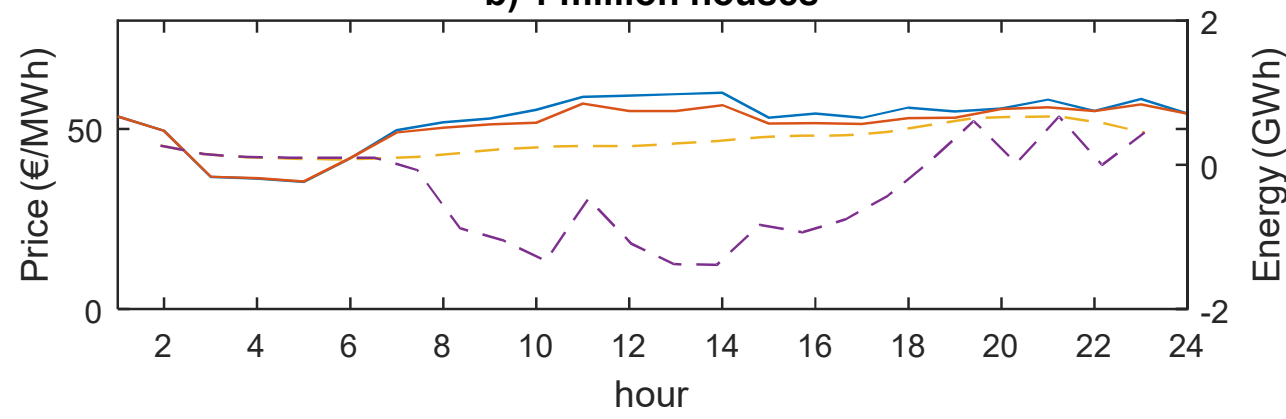

c) 8 million houses

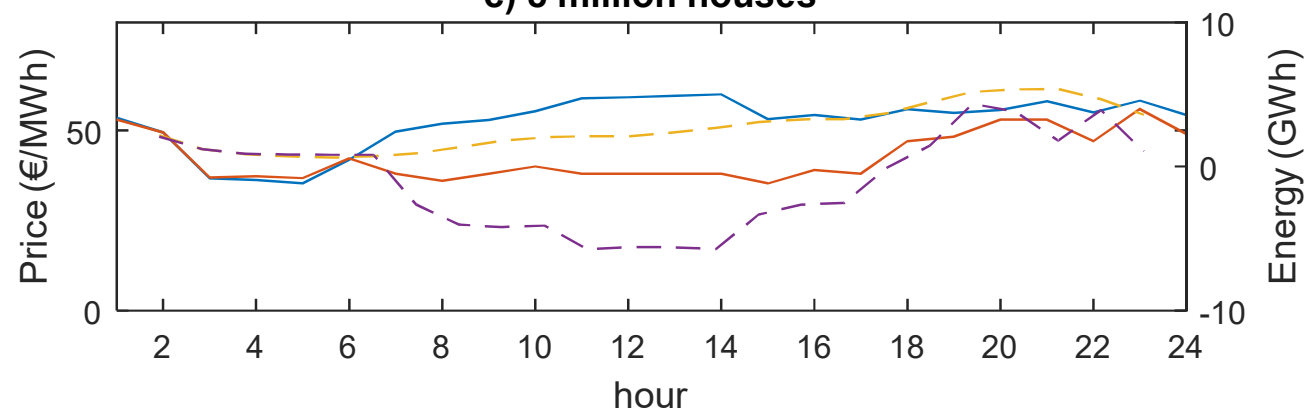

Fig. 13. Aggregator energy transactions and effect on energy price for the representative day of July (Case study B), a) for 40000, b) 1000000 and c) 8000000 houses.

The third case study implements the stochastic model with 3 scenarios per hour. Fig. 14 shows the aggregator behavior for the three scenarios at winter time for one million houses. It can be seen that these scenarios have even larger variability and price differences in comparison with previous case studies, with prices ranging from 0 to $80 € / \mathrm{MWh}$ approximately. In other words, the stochastic scenarios can take into account other cases that disappeared in the deterministic ones due to the averaging (for instance, cases related to weekends are averaged out with the working days, 
C. Calvillo, A. Sánchez, J. Villar, F. Martín. Optimal planning and operation of aggregated distributed energy resources with market participation. Applied Energy. vol. 182, pp. 340-357, November 2016. [Online: August 2016] JCR impact factor: 7.182 (2016)

reducing peaks and valleys in the price curves).This provokes the district to install more battery capacity, so the aggregator can buy more energy at the early hours of the day, when the prices are lower or even zero, to store it and use it (or sell it) when prices are higher. This behavior also flattens slightly the energy price curves (red lines).

\section{a) Sc1 - 1 million houses}

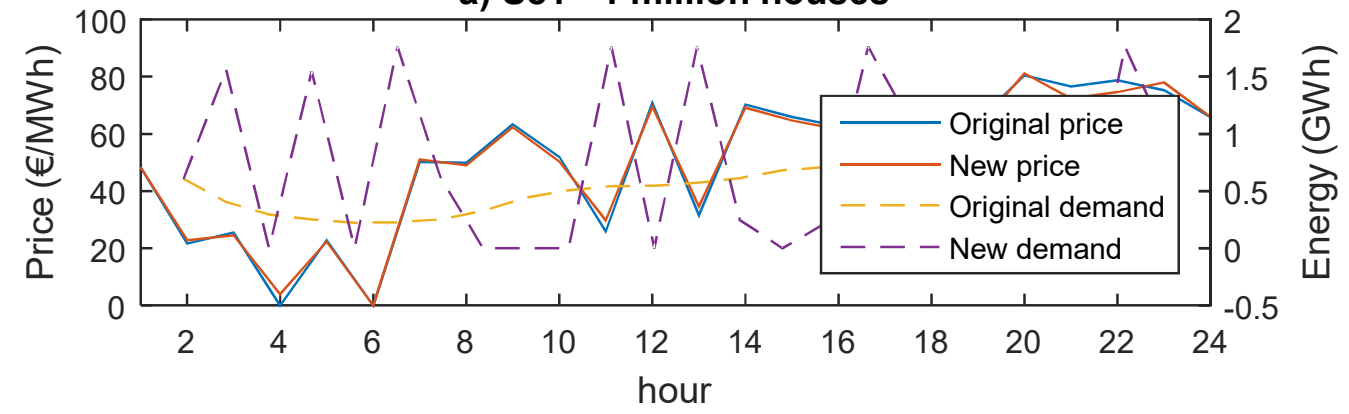

b) Sc2 - 1 million houses

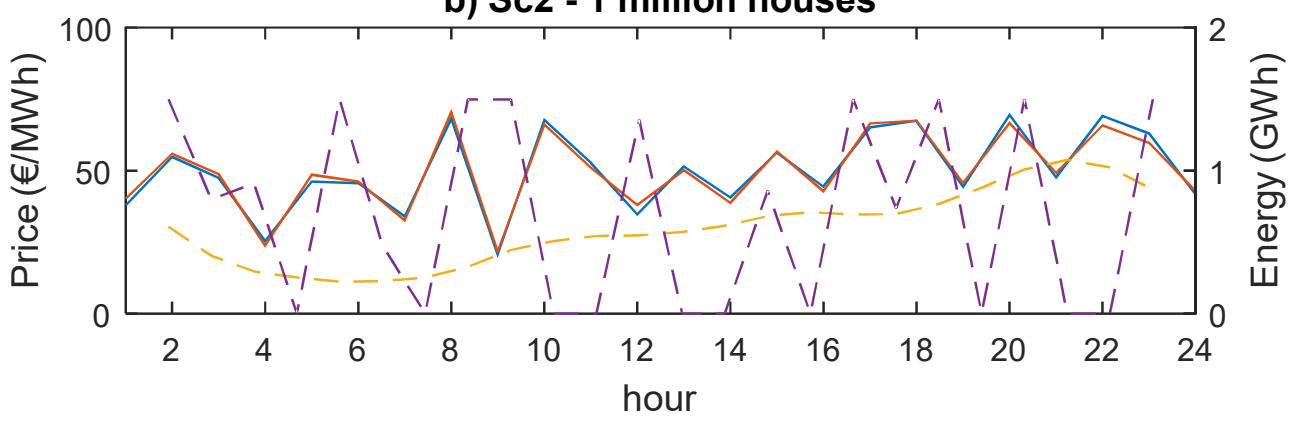

c) Sc3 - 1 million houses

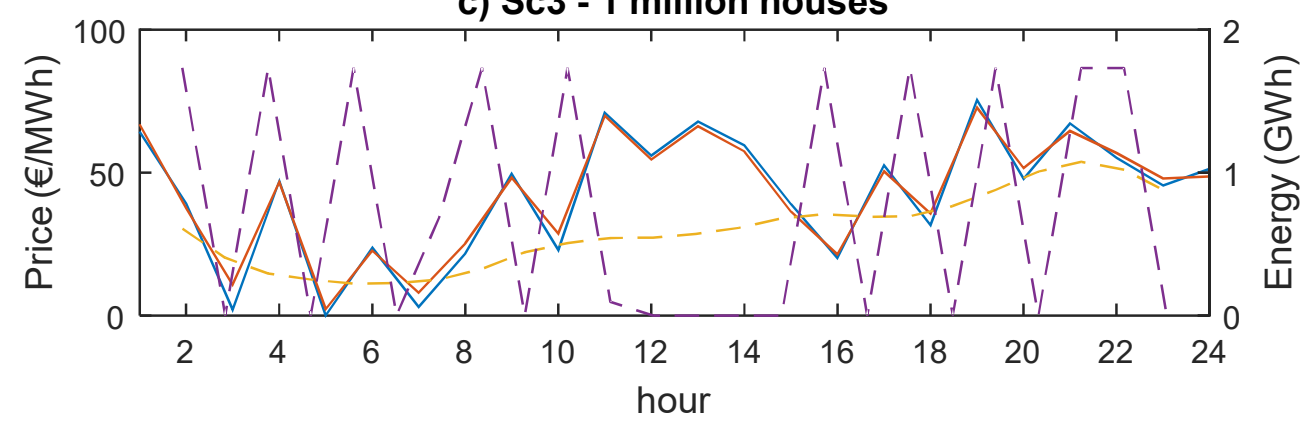

Fig. 14. Aggregator energy transactions and effect on energy price for the representative day of January (Case study C), a) for Sc1, b) Sc2 and c) Sc3, all with 1000000 houses.

The aggregator operation on the representative summer day is depicted in Fig. 15, again with a district size of 1 million houses. The first figure (a) shows the price curve of scenario 1 . Here, the 
C. Calvillo, A. Sánchez, J. Villar, F. Martín. Optimal planning and operation of aggregated distributed energy resources with market participation. Applied Energy. vol. 182, pp. 340-357, November 2016. [Online: August 2016] JCR impact factor: 7.182 (2016)

original price curve is flatter than in winter, and thus, there is not much load shifting throughout the day and most of the energy produced by the PV systems has been sold back to the grid. Scenario 2 (Fig. 15b) presents a slightly larger variability in prices as in winter scenarios. This produces more load shifting and selling energy back to the grid when the electricity price is higher. Lastly, scenario 3 (c) has a slightly flatter price curve, and the aggregator strategy is similar than in scenario 1. It can be noted that the aggregator strategy overall tends to decrease the electricity price in summer time, by selling energy back to the grid. 
C. Calvillo, A. Sánchez, J. Villar, F. Martín. Optimal planning and operation of aggregated distributed energy resources with market participation. Applied Energy. vol. 182, pp. 340-357, November 2016. [Online: August 2016] JCR impact factor: 7.182 (2016)

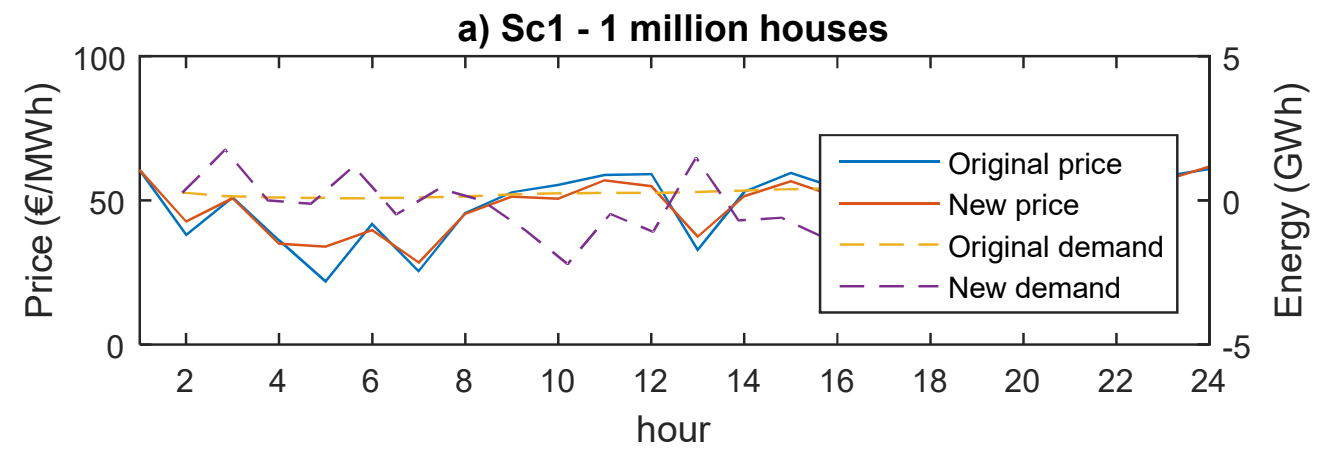

b) Sc2 - 1 million houses

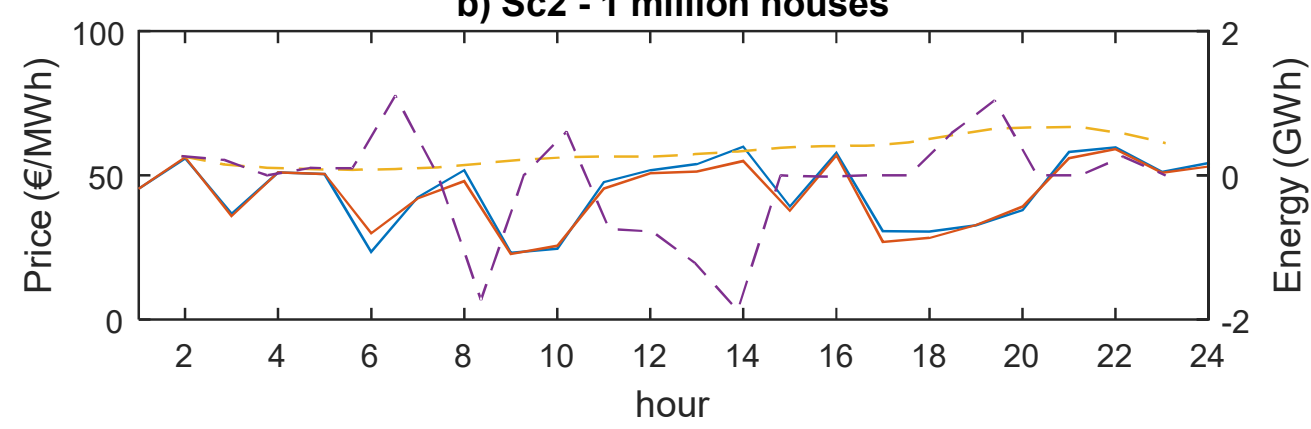

c) Sc3 - 1 million houses

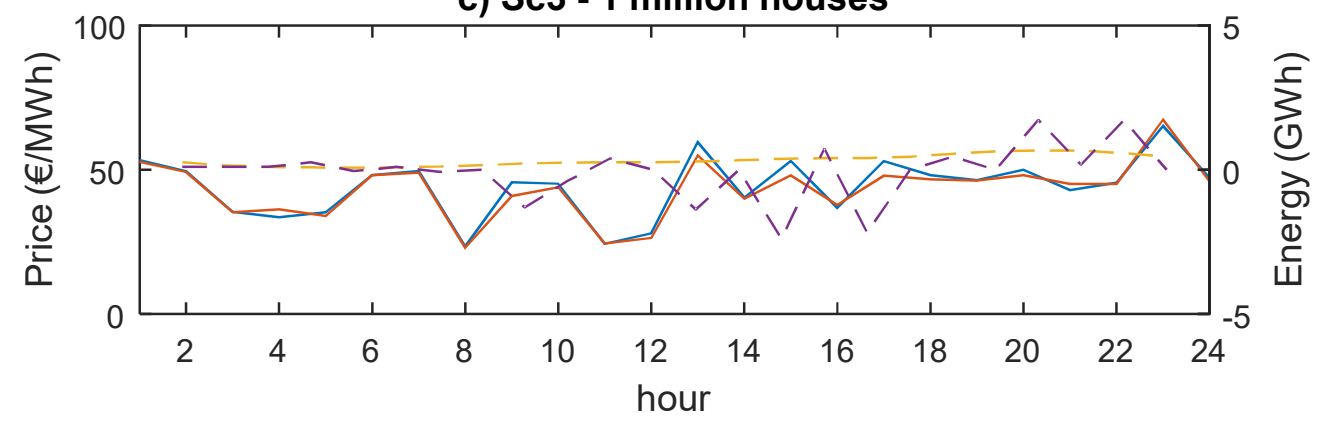

Fig. 15. Aggregator energy transactions and effect on energy price for the representative day of July (Case study C), a) for Sc1, b) Sc2 and c) Sc3, all with 1000000 houses.

As shown in the above figures, the aggregator behaves similarly in all case studies: on the one hand, it reduces the energy bought from the market at the middle of the day, which is also when the PV production is larger; on the other hand, it shifts load from the peak hours to the off-peak ones, using the battery storage and/or the demand response strategy. This load shifting makes the electricity price curve flatter, increasing the price of the off-peak hours (due to a greater demand) and decreasing the price at peak hours (due to a lower demand), with a net cost reduction for the 
C. Calvillo, A. Sánchez, J. Villar, F. Martín. Optimal planning and operation of aggregated distributed energy resources with market participation. Applied Energy. vol. 182, pp. 340-357, November 2016. [Online: August 2016] JCR impact factor: 7.182 (2016)

aggregator. Moreover, batteries have only been installed when load shifting still allows for prices differences that make battery investments profitable, and it can be seen that the price change increases with the amount of aggregated resources.

\subsection{Discussion and case study comparison}

Different district sizes have been considered in all case studies, taking the 4 household types, described in section 4.1, as the base load. For instance, a district with 100000 clients is disaggregated into 25000 clients per each client type. To have a better understanding of the magnitude of the districts in comparison to the total market size, the respective market share for all considered districts has been calculated with (37) as the mean of the hourly market shares. The hourly market share has been computed as the original demand (without implementing any DER or management of any sort) of the considered district at a particular hour of a month, over the average demand of the Spanish system at the same hour, considering all the days of that month. The maximum number of clients implementing DER systems considered in this study is 8 million. This corresponds to around $15 \%$ of the total demand of the Spanish system. The rest of the system demand goes to other residential clients (approx. 25\%) and to industrial and commercial clients (approx. 60\%) [46].

marketShare $=\frac{\sum_{m} \sum_{h}\left(\frac{\text { vOriginalDemand }_{m, h}}{\text { pAvgSystemDemand }} m, h\right.}{m * h}$

The average change on electricity prices due to the aggregator actions and the impact on the electric energy costs in the considered districts have been computed as well. The average price change and the absolute price change have been computed with (38) and (39) respectively, where the average of the original prices has been computed with (40). Also, the average energy weighted system price change is calculated with $(41)-(43)$. The change in electricity costs is calculated with (41).

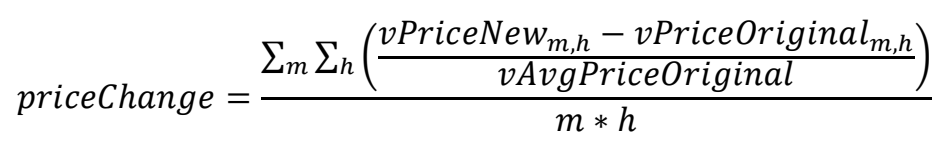


C. Calvillo, A. Sánchez, J. Villar, F. Martín. Optimal planning and operation of aggregated distributed energy resources with market participation. Applied Energy. vol. 182, pp. 340-357, November 2016. [Online: August 2016] JCR impact factor: 7.182 (2016)

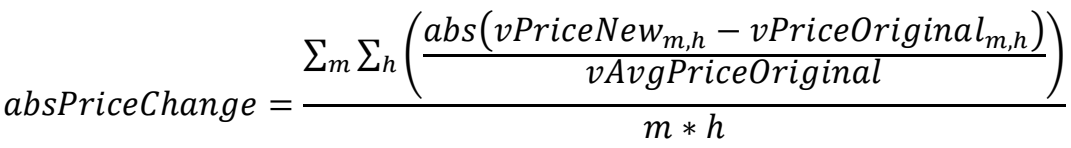

$$
\begin{aligned}
& v \text { AvgPriceOriginal }=\frac{\sum_{m} \sum_{h}\left(\text { vPriceOriginal }_{m, h}\right)}{m * h}
\end{aligned}
$$

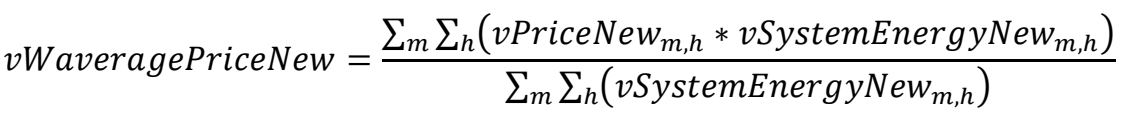

$$
\begin{aligned}
& \text { vWaveragePriceOriginal }=\frac{\sum_{m} \sum_{h}\left(\text { vPriceOriginal }_{m, h} * \text { vSystemEnergyOriginal }_{m, h}\right)}{\sum_{m} \sum_{h}\left(\text { vSystemEnergyOriginal }_{m, h}\right)} \\
& \text { SystemPriceChange }=\frac{v \text { WaveragePriceNew }-v \text { WaveragePriceOriginal }}{v \text { WaveragePriceOriginal }} * 100 \\
& \text { enCostChange }=\frac{\sum_{m} \sum_{h}\left(\begin{array}{c}
\text { vPriceNew }_{m, h} * \text { vEnergyNew }_{m, h} \\
\text { - } \text { PriceOriginal }_{m, h} * \text { vEnergyOriginal }_{m, h}
\end{array}\right)}{\sum_{m} \sum_{h}\left(\text { vPriceOriginal }_{m, h} * \text { vEnergyOriginal }_{m, h}\right)}
\end{aligned}
$$

The results of the analyzed case studies are presented in Table 5 and Table 6 . In Case study A, the former table shows how the installed capacity of the PV and HP grew almost linearly with the number of houses, yet the battery has been very little or not implemented in most cases, since the prices differences after load management have not been enough to compensate batteries investment prices. The system total costs (Table 6), including energy and DER costs (calculated with (1)), presented a similar linear pattern, with lower slope, than the PV and HP installed capacity, meaning that the aggregator's economic benefits of managing larger districts are greater than the increased costs of a greater amount of loads and distributed resources.

Table 5

DER installed capacity for all case studies.

\begin{tabular}{cc|cccccccccc}
$\begin{array}{c}\text { Number } \\
\text { of clients }\end{array}$ & $\begin{array}{c}\text { Market } \\
\text { share }\end{array}$ & \multicolumn{3}{c}{ PV (MW) } & \multicolumn{3}{c}{ Battery (MWh) } & \multicolumn{3}{c}{ HP (MW) } \\
(millions) & $\mathbf{( \% )}$ & A & B & C & A & B & C & A & B & C \\
\hline 0.04 & $0.076 \%$ & 110 & 124 & 96 & 0 & 0 & 58 & 17 & 17 & 16 \\
0.1 & $0.19 \%$ & 279 & 327 & 234 & 9 & 0 & 131 & 42 & 43 & 39
\end{tabular}


C. Calvillo, A. Sánchez, J. Villar, F. Martín. Optimal planning and operation of aggregated distributed energy resources with market participation. Applied Energy. vol. 182, pp. 340-357, November 2016. [Online: August 2016] JCR impact factor: 7.182 (2016)

\begin{tabular}{cc|ccccccccc}
0.2 & $0.38 \%$ & 540 & 635 & 477 & 16 & 0 & 255 & 83 & 86 & 78 \\
0.4 & $0.76 \%$ & 1053 & 1234 & 891 & 27 & 0 & 437 & 167 & 171 & 154 \\
1 & $1.9 \%$ & 2621 & 3028 & 1917 & 65 & 0 & 1282 & 412 & 426 & 399 \\
2 & $3.8 \%$ & 5227 & 5954 & 3810 & 10 & 0 & 2212 & 834 & 856 & 739 \\
4 & $7.6 \%$ & 9651 & 10469 & 7570 & 11 & 0 & 2985 & 1667 & 1667 & 1560 \\
8 & $15.2 \%$ & 17662 & 18185 & 15253 & 0 & 0 & 4903 & 3335 & 3335 & 3240
\end{tabular}

Table 6

Total system cost (energy and DER) for all case studies.

\begin{tabular}{cc|rrr}
$\begin{array}{c}\text { Number } \\
\text { of clients } \\
\text { (millions) }\end{array}$ & $\begin{array}{c}\text { Market } \\
\text { share } \\
\mathbf{( \% )}\end{array}$ & \multicolumn{3}{|c}{ Total costs (M€) } \\
\hline 0.04 & $0.076 \%$ & 760.77 & \multicolumn{1}{c}{ B } & \multicolumn{1}{c}{ C } \\
\hline 0.1 & $0.19 \%$ & 1824.15 & 1870.3 & 1581.6 \\
0.2 & $0.38 \%$ & 3635.94 & 3726.2 & 3078.9 \\
0.4 & $0.76 \%$ & 7277.55 & 7440.1 & 5953.7 \\
1 & $1.9 \%$ & 18083.2 & 18237.1 & 12004.3 \\
2 & $3.8 \%$ & 36192.1 & 36574.5 & 24225.5 \\
4 & $7.6 \%$ & 72952.13 & 73576.4 & 58050.3 \\
8 & $15.2 \%$ & 147378.07 & 149218.5 & 127128
\end{tabular}

In Case study B, battery storage has not been implemented in any of the district sizes considered while the entire DER installed capacity grew with the number of clients. The difference in prices during the day, especially at winter time, makes load shifting more profitable, but the differences have not been large enough to implement battery systems. Regarding the total system costs (Table 6), Case B values were slightly greater than those of Case A. This was a result of both the slightly higher average price and the slightly higher prices at the off-peak hours from the input parameters.

Focusing on Case $\mathrm{C}$, it can be seen that in comparison with the deterministic cases, the HP installed capacity was slightly smaller, especially in big districts. In addition, the PV capacity was smaller for all district sizes, especially in the larger districts. However, the main difference is in the battery 
C. Calvillo, A. Sánchez, J. Villar, F. Martín. Optimal planning and operation of aggregated distributed energy resources with market participation. Applied Energy. vol. 182, pp. 340-357, November 2016. [Online: August 2016] JCR impact factor: 7.182 (2016)

systems that increased significantly for all the analyzed district sizes. This has been due to the greater variability and difference in prices provided by the stochastic scenarios, as shown in Fig. 14 and Fig. 15. Lastly, the total system costs were slightly smaller (especially with medium to large amounts of aggregated resources) than in the previous cases. Once again, this last phenomenon has been produced by taking advantage of the larger price variability and the lower minimum price (see Fig. 14) in comparison with case studies A and B.

Table 7 shows the average change on electricity prices due to the aggregator actions and the repercussion on the electric energy costs of the system (calculated with (38) - (43)). From Table 7 and the figures of the previous section, it can be seen that distributed generation such as PV panels tends to reduce the overall electricity consumption $(32-68 \%$ depending on the district size and the case study), reducing the electricity price for all district sizes. However, it is evident that the price change is more significant for larger district sizes, as the market share is larger.

Note that all market participants affect the market price since they move the clearing point on the RDC. In addition, even for small agents, if the slopes of the RDC faced are large, they can have large impacts on the price (as proved in [52] and [53]).

It is important to remark that the adequate computation of the price-taker error is not straightforward and requires, at least, to create two more models: One price-maker with fixed energy prices, where the resulting planning and operation variables are saved (the energy prices and costs will be erroneous with respect to reality), and a new price-maker model that takes the planning and operation from the "price-taker", evaluating the change on prices according to this operation. This will give the new energy prices and costs, and thus, the error can be calculated. For the sake of brevity, such computation is not developed in this paper. Nevertheless, it can be seen that for large DER aggregations, a price-taker approach could have an important error and is likely to provide non-meaningful results. However, for smaller aggregations (less than 100000 houses) a price-taker approach could be acceptable.

\section{Table 7}

Effect on electricity prices for all case studies. 
C. Calvillo, A. Sánchez, J. Villar, F. Martín. Optimal planning and operation of aggregated distributed energy resources with market participation. Applied Energy. vol. 182, pp. 340-357, November 2016. [Online: August 2016] JCR impact factor: 7.182 (2016)

\begin{tabular}{|c|c|c|c|c|c|c|c|c|}
\hline \multirow{2}{*}{$\begin{array}{l}\text { Number } \\
\text { of clients } \\
\text { (millions) }\end{array}$} & \multirow{2}{*}{$\begin{array}{c}\text { Market } \\
\text { share } \\
\text { (\%) }\end{array}$} & \multicolumn{3}{|c|}{ Average price change (\%) } & \multicolumn{3}{|c|}{ Average abs. price change (\%) } & \multirow{2}{*}{$\begin{array}{c}\text { Average } \\
\text { system price } \\
\text { change (\%) }\end{array}$} \\
\hline & & $\mathbf{A}$ & B & C & $\mathbf{A}$ & B & C & \\
\hline 0.04 & $0.076 \%$ & $-0.05 \%$ & $-0.05 \%$ & $-0.04 \%$ & $0.10 \%$ & $0.09 \%$ & $0.20 \%$ & $-0.07 \%$ \\
\hline 0.1 & $0.19 \%$ & $-0.12 \%$ & $-0.15 \%$ & $-0.08 \%$ & $0.25 \%$ & $0.23 \%$ & $0.44 \%$ & $-0.14 \%$ \\
\hline 0.2 & $0.38 \%$ & $-0.22 \%$ & $-0.28 \%$ & $-0.13 \%$ & $0.49 \%$ & $0.46 \%$ & $0.87 \%$ & $-0.26 \%$ \\
\hline 0.4 & $0.76 \%$ & $-0.42 \%$ & $-0.55 \%$ & $-0.23 \%$ & $1.02 \%$ & $0.90 \%$ & $1.60 \%$ & $-0.50 \%$ \\
\hline 1 & $1.9 \%$ & $-1.00 \%$ & $-1.39 \%$ & $-0.50 \%$ & $2.35 \%$ & $2.26 \%$ & $3.94 \%$ & $-1.20 \%$ \\
\hline 2 & $3.8 \%$ & $-2.19 \%$ & $-2.73 \%$ & $-1.08 \%$ & $4.83 \%$ & $4.61 \%$ & $7.39 \%$ & $-2.59 \%$ \\
\hline 4 & $7.6 \%$ & $-4.15 \%$ & $-4.71 \%$ & $-2.48 \%$ & $8.81 \%$ & $8.32 \%$ & $13.31 \%$ & $-4.81 \%$ \\
\hline 8 & $15.2 \%$ & $-7.94 \%$ & $-8.40 \%$ & $-6.19 \%$ & $16.07 \%$ & $14.93 \%$ & $23.56 \%$ & $-8.88 \%$ \\
\hline
\end{tabular}

Comparing the change on electricity prices, Case study A had a slightly smaller decrement in comparison with Case study B, but the absolute price change has been slightly larger in all district sizes. For Case study $\mathrm{C}$, it can be seen that the high variability on the original prices can make the average price change to seem small in comparison with previous case studies at certain district sizes; however, the absolute change showed more significant price changes, especially with the larger district sizes, that can be above the $23 \%$. In other words, in Case $\mathrm{C}$ the price decrements have been more compensated with the prices increments, unlike the other cases that produced more decrements than increments on the electricity price.

Table 8 shows the average changes in electric energy costs for the district (calculated with (44)). The savings in Case study A were lower than in Case study B for all district sizes, mainly caused by the higher average prices, and the greater PV capacity installed in case study B. Regarding Case study $\mathrm{C}$, the average savings for all district sizes were $62 \%$ approximately. It is important to remark that, for all case studies, the electric energy cost reduction has been greater with smaller number of clients and this amount decreased as the amount of clients increased. This has been caused, on the one hand, due to the overall lower prices (produced with larger district sizes) that generate a lower profit for selling energy (with smaller districts, the price for selling energy will be higher because less energy has been taken from the electric system and the adjustment of the residual demand curve is smaller, see section 4.2.3). On the other hand, the benefit of buying energy at off- 
C. Calvillo, A. Sánchez, J. Villar, F. Martín. Optimal planning and operation of aggregated distributed energy resources with market participation. Applied Energy. vol. 182, pp. 340-357, November 2016. [Online: August 2016] JCR impact factor: 7.182 (2016)

peak times has been reduced with the flatter price curves (see section 5.1). Note that the savings in electricity costs might not be representative of the savings on total costs, as other aggregator costs (investment in DER systems, maintenance, etc.) have also been taken into account.

\section{Table 8}

Effect on electric energy cost for all case studies.

\begin{tabular}{cc|ccc}
$\begin{array}{c}\text { Number } \\
\text { of clients } \\
\text { (millions) }\end{array}$ & $\begin{array}{c}\text { Market } \\
\text { share }\end{array}$ & \multicolumn{4}{|c}{ Electric Energy Cost change (\%) } \\
\hline 0.04 & A & B & C \\
\hline 0.1 & $0.076 \%$ & $-65.71 \%$ & $-84.92 \%$ & $-100.56 \%$ \\
0.2 & $0.19 \%$ & $-66.18 \%$ & $-92.48 \%$ & $-86.02 \%$ \\
0.4 & $0.38 \%$ & $-63.21 \%$ & $-88.19 \%$ & $-80.98 \%$ \\
1 & $1.9 \%$ & $-59.58 \%$ & $-84.06 \%$ & $-68.75 \%$ \\
2 & $3.8 \%$ & $-56.29 \%$ & $-78.71 \%$ & $-55.17 \%$ \\
4 & $7.6 \%$ & $-46.84 \%$ & $-75.40 \%$ & $-46.16 \%$ \\
8 & $15.2 \%$ & $-35.95 \%$ & $-45.95 \%$ & $-24.10 \%$
\end{tabular}

The outcomes of the case studies previously presented have been illustrated in Fig. 16 and Fig. 17. In the former figure, it can be seen how the PV and HP installed capacities tend to grew steadily with the larger number of clients, and that there was no large difference between case studies. The battery systems, on the contrary, varied significantly among case studies and district sizes, being Case study $\mathrm{C}$ the one that implemented such systems the most. This has been produced by the high variability of prices, making investment in battery for load-shifting more profitable, as shown in previous subsection. 
C. Calvillo, A. Sánchez, J. Villar, F. Martín. Optimal planning and operation of aggregated distributed energy resources with market participation. Applied Energy. vol. 182, pp. 340-357, November 2016. [Online: August 2016] JCR impact factor: 7.182 (2016)

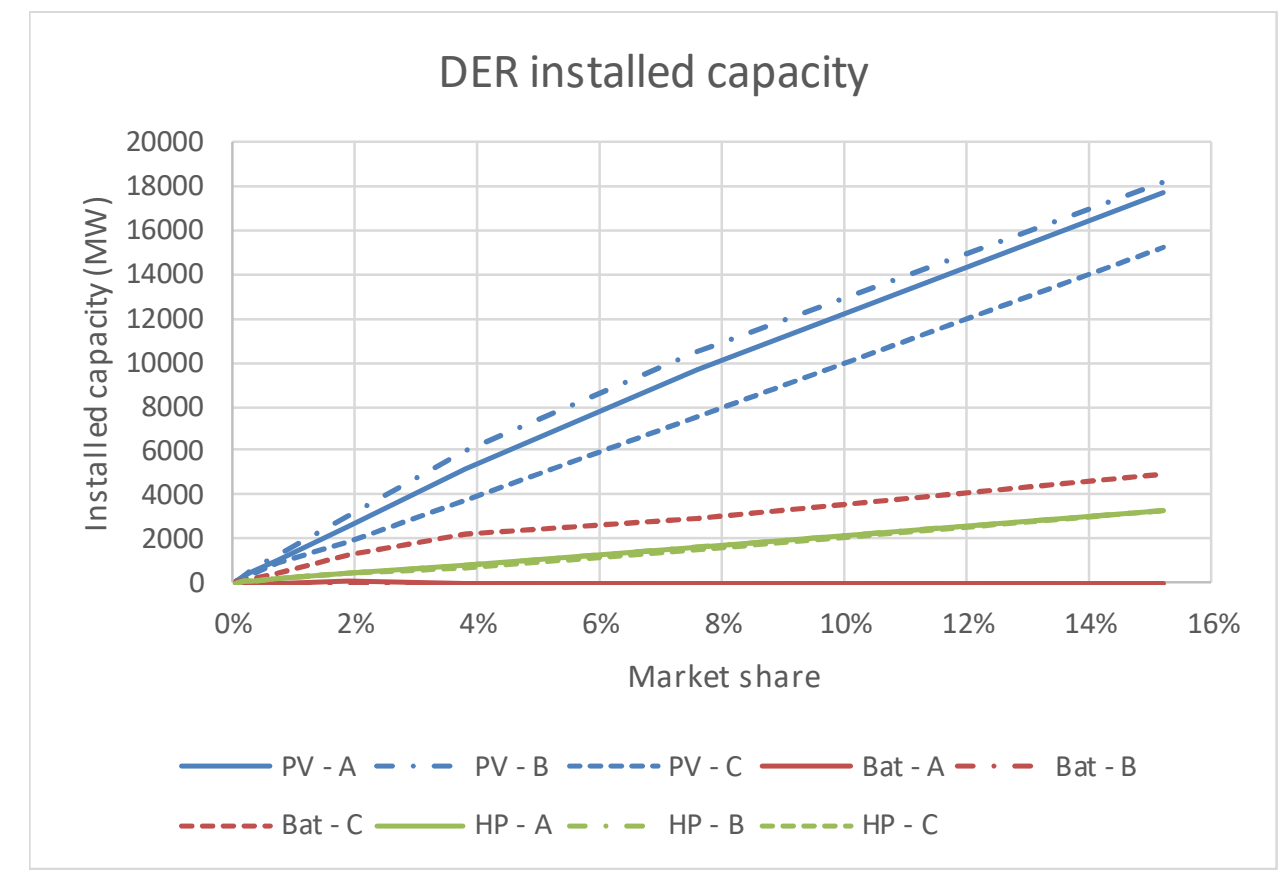

Fig. 16. DER installed capacity for all case studies.

The total system costs of all case studies are shown Fig. 17 (taken from Table 6), showing that the costs grow almost linearly with the size of the district for all cases.

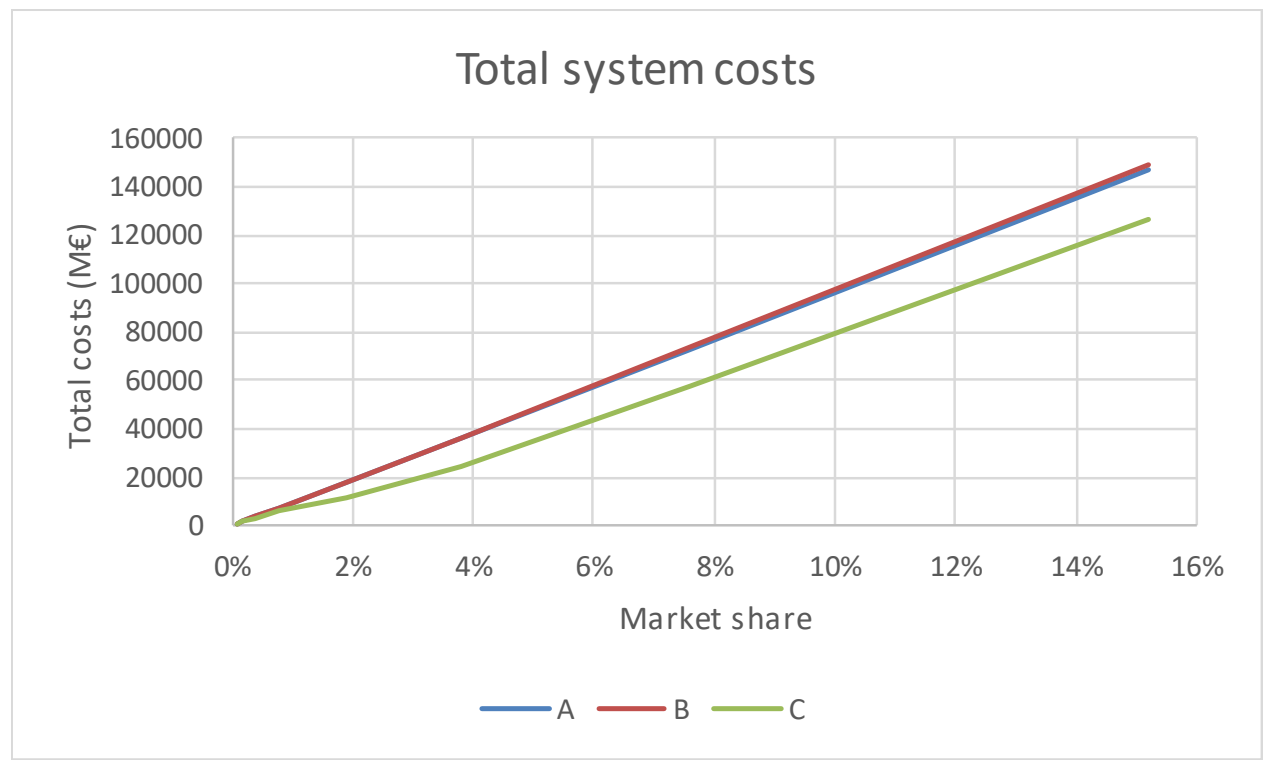

Fig. 17. Total system costs for all case studies (at the end of the 20 years project lifespan). 
C. Calvillo, A. Sánchez, J. Villar, F. Martín. Optimal planning and operation of aggregated distributed energy resources with market participation. Applied Energy. vol. 182, pp. 340-357, November 2016. [Online: August 2016] JCR impact factor: 7.182 (2016)

To further analyze the effect of size in the aggregated resources, Table 9 shows the total aggregator costs (including energy and DER system costs) per house at the end of the project lifespan (20 years) for the different district sizes and its equivalent market shares.

Table 9

Total costs per household.

\begin{tabular}{|c|c|c|c|c|}
\hline $\begin{array}{l}\text { Number of } \\
\text { clients } \\
\text { (millions) }\end{array}$ & $\begin{array}{c}\text { Market } \\
\text { share } \\
(\%)\end{array}$ & $\begin{array}{c}\text { Case study } \\
\qquad \begin{array}{c}\text { A } \\
(k €)\end{array}\end{array}$ & $\begin{array}{c}\text { Case study } \\
\text { B } \\
(k €)\end{array}$ & $\begin{array}{c}\text { Case study } \\
\qquad \begin{array}{c}\text { C } \\
(k €)\end{array}\end{array}$ \\
\hline 0.04 & $0.076 \%$ & 19.02 & 19.00 & 16.77 \\
\hline 0.1 & $0.19 \%$ & 18.24 & 18.70 & 15.82 \\
\hline 0.2 & $0.38 \%$ & 18.18 & 18.63 & 15.39 \\
\hline 0.4 & $0.76 \%$ & 18.19 & 18.60 & 14.88 \\
\hline 1 & $1.9 \%$ & 18.08 & 18.24 & 12.00 \\
\hline 2 & $3.8 \%$ & 18.10 & 18.29 & 12.11 \\
\hline 4 & $7.6 \%$ & 18.24 & 18.39 & 14.51 \\
\hline 8 & $15.2 \%$ & 18.42 & 18.65 & 15.89 \\
\hline
\end{tabular}

Case studies A and B had larger costs per household in comparison with Case study C. This can be explained by the larger variability of prices on the stochastic scenarios. The total system costs per house decreased as the number of aggregated resources increased (the aggregator had greater market share and a larger amount of manageable resources), up to a point when a minimum cost has been reached (around $1-2$ million of clients), then the costs increased slightly. Once again, this phenomenon can be explained by the overall lower prices and flatter price curves, where the aggregator benefited from buying energy cheaper, but his income of selling energy has been affected at the same time (the price is cheaper and the income is lower). Hence, an optimal point has been achieved where the aggregator found the best compromise in costs and profits, as can be seen in Fig. 18. 
C. Calvillo, A. Sánchez, J. Villar, F. Martín. Optimal planning and operation of aggregated distributed energy resources with market participation. Applied Energy. vol. 182, pp. 340-357, November 2016. [Online: August 2016] JCR impact factor: 7.182 (2016)

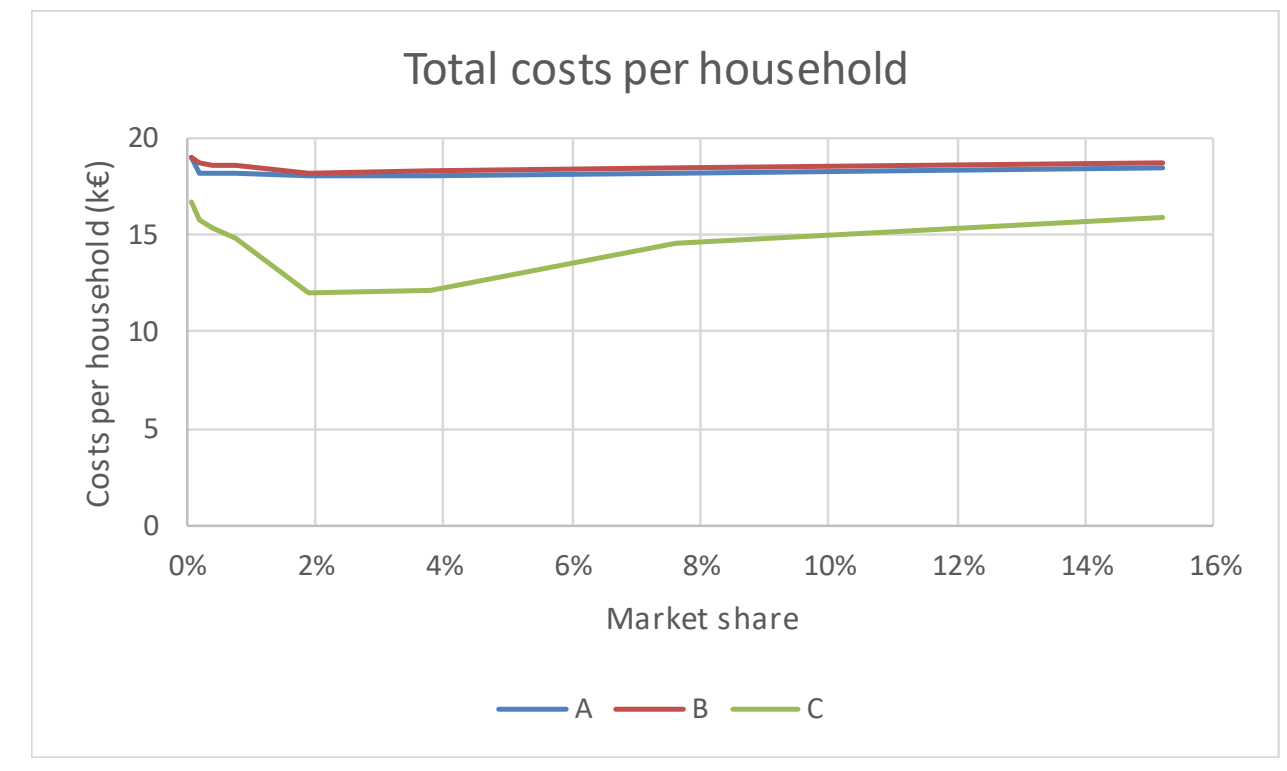

Fig. 18. Total costs per household (at the end of the 20 years project lifespan).

Additionally, the total costs of the proposed systems have been compared with a base case following a business-as-usual approach (not implementing any DER systems). The base case total cost has been calculated with (1) but with DER capacity and related costs equal to zero (the only terms considered are $v \operatorname{CostEE}, v \operatorname{CostET}, v \operatorname{CostPowE}$ and $v \operatorname{CostPowT})$. Hence, this comparison served to assess the benefits of the optimal management of loads and DER systems under different aggregation scales. To create a fair assessment, each case study has been compared with its own base case (equal input parameters) without implementing any distributed energy resources, as described in (45). The results of such comparisons can be found in Table 10 and have been illustrated in Fig. 19. It can be seen that, similarly to previous analysis, profitability increased with market share up to $3-4 \%$, where the maximum benefits have been achieved $(31 \%, 28 \%$ and $51 \%$ for case studies A, B and C, respectively).

$$
\text { totalSavings }=\frac{v \text { TotalCostBaseCase }- \text { vTotalCostNew }}{\text { vTotalCostBaseCase }}
$$

The results presented in both Table 9 and Table 10 suggest that an aggregator can benefit significantly from participating in the market, even with a relatively small market share (less than $1 \%)$. 
C. Calvillo, A. Sánchez, J. Villar, F. Martín. Optimal planning and operation of aggregated distributed energy resources with market participation. Applied Energy. vol. 182, pp. 340-357, November 2016. [Online: August 2016] JCR impact factor: 7.182 (2016)

Table 10

Percentage of total savings in comparison with the base system costs of each case study.

\begin{tabular}{|c|c|c|c|c|}
\hline $\begin{array}{l}\text { Number of } \\
\text { clients } \\
\text { (millions) }\end{array}$ & $\begin{array}{c}\text { Market } \\
\text { share } \\
(\%)\end{array}$ & $\begin{array}{c}\text { Case study } \\
\text { A } \\
(\%)\end{array}$ & $\begin{array}{c}\text { Case study } \\
\text { B } \\
(\%)\end{array}$ & $\begin{array}{c}\text { Case study } \\
\text { C } \\
(\%)\end{array}$ \\
\hline 0.04 & $0.076 \%$ & $27.9 \%$ & $24.8 \%$ & $32.0 \%$ \\
\hline 0.1 & $0.19 \%$ & $30.9 \%$ & $25.9 \%$ & $35.8 \%$ \\
\hline 0.2 & $0.38 \%$ & $31.1 \%$ & $26.2 \%$ & $37.5 \%$ \\
\hline 0.4 & $0.76 \%$ & $31.0 \%$ & $26.3 \%$ & $39.6 \%$ \\
\hline 1 & $1.9 \%$ & $31.5 \%$ & $27.8 \%$ & $51.3 \%$ \\
\hline 2 & $3.8 \%$ & $31.4 \%$ & $27.6 \%$ & $50.9 \%$ \\
\hline 4 & $7.6 \%$ & $30.9 \%$ & $27.1 \%$ & $41.1 \%$ \\
\hline 8 & $15.2 \%$ & $30.2 \%$ & $26.1 \%$ & $35.5 \%$ \\
\hline
\end{tabular}

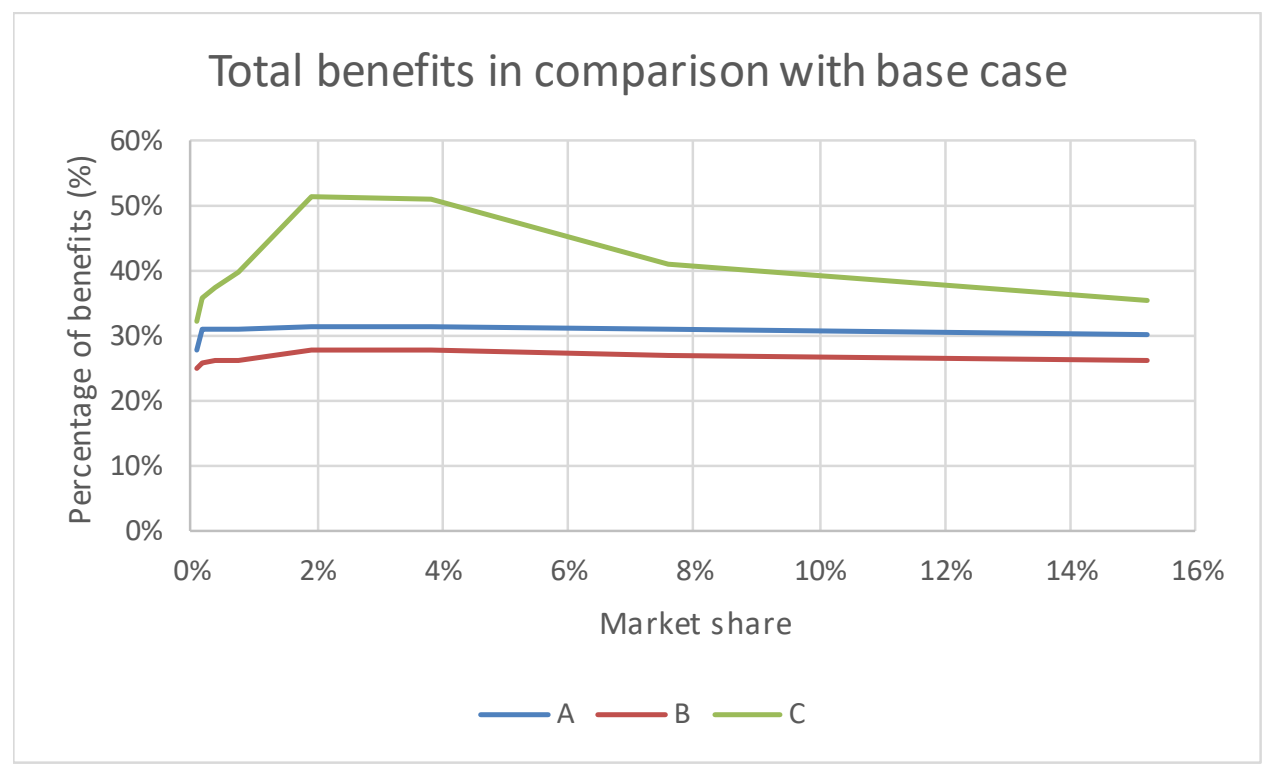

Fig. 19. Percentage of economic benefits in comparison with the base case.

Lastly, to analyze the effect of the volume of the aggregated resources, the total cost per client (taken from Table 9) at all district sizes has been compared with the cost at the smallest considered district, as in (46). This index shows more clearly the impact of market share into the final costs. 
C. Calvillo, A. Sánchez, J. Villar, F. Martín. Optimal planning and operation of aggregated distributed energy resources with market participation. Applied Energy. vol. 182, pp. 340-357, November 2016. [Online: August 2016] JCR impact factor: 7.182 (2016)

Table 11 summarizes such effects for the three case studies. It can be seen that the benefit can get up to $28 \%$ in costs savings with a market share of around $2 \%$ in case study C. However, the deterministic cases did not show such a large benefit due to market share. This phenomenon occurred because the lower variability on prices provided less incentives to exercise market power.

$$
\text { savingsPerClient }=\frac{v \text { CostClientSmallestDistrict }-v \text { CostClientNewDistrict }}{v \text { CostClientSmallestDistrict }}
$$

Table 11

Percentage of savings per house in comparison with the smallest district.

\begin{tabular}{cc|ccc}
$\begin{array}{c}\text { Number of } \\
\text { clients } \\
\text { (millions) }\end{array}$ & $\begin{array}{c}\text { Market } \\
\text { share } \\
\mathbf{( \% )}\end{array}$ & $\begin{array}{c}\text { Case study } \\
\mathbf{A}\end{array}$ & $\begin{array}{c}\text { Case study } \\
\mathbf{( \% )}\end{array}$ & $\begin{array}{c}\text { Case study } \\
\mathbf{( \% )}\end{array}$ \\
\hline 0.04 & $0.076 \%$ & $0 \%$ & $0 \%$ & $\mathbf{C}$ \\
0.1 & $0.19 \%$ & $4.09 \%$ & $1.54 \%$ & $5.66 \%$ \\
0.2 & $0.38 \%$ & $4.41 \%$ & $1.92 \%$ & $8.17 \%$ \\
0.4 & $0.76 \%$ & $4.34 \%$ & $2.08 \%$ & $11.22 \%$ \\
1 & $1.9 \%$ & $4.92 \%$ & $3.99 \%$ & $28.40 \%$ \\
2 & $3.8 \%$ & $4.85 \%$ & $3.73 \%$ & $27.75 \%$ \\
4 & $7.6 \%$ & $4.11 \%$ & $3.16 \%$ & $13.44 \%$ \\
8 & $15.2 \%$ & $3.14 \%$ & $1.80 \%$ & $5.21 \%$
\end{tabular}

\section{Concluding remarks}

This paper presents two different optimization models corresponding to three different approaches (stochastic, deterministic with the average scenario and deterministic with the most likely scenario out of the stochastic ones) for planning and operating distributed energy resources managed by a price-maker aggregator, participating in the electricity market.

From the numerical results, it can be concluded that the aggregation of distributed energy resources can be very profitable for both aggregator and prosumers. With relatively small market shares ( $1 \%$ 
C. Calvillo, A. Sánchez, J. Villar, F. Martín. Optimal planning and operation of aggregated distributed energy resources with market participation. Applied Energy. vol. 182, pp. 340-357, November 2016. [Online: August 2016] JCR impact factor: 7.182 (2016)

$-2 \%$ ), the economic benefits of such approach can get up to $51 \%$ with respect to the case of not installing DER systems and managing load. It is important to remark that these economic benefits are for the aggregator or retailer participating in the market. However, it is sensible to consider that these benefits could be translated to a large extent to the final prosumer as well.

Indeed, the aggregator's price-maker approach is not commonly found in the literature, as it represents a more complex non-linear and/or mixed-integer problem to solve (mainly addressed by metaheuristic methods). However, it can be seen in the analysis developed that the market price change is related to the size of the aggregator, and that this price change affects both the costs of buying energy and the profit of selling energy at a wholesale level. Therefore, even for relatively small aggregations, the impact on electricity prices should always be considered in order to find optimal strategies.

Comparing the models presented in this paper, the deterministic case studies proposed delivered similar results in the final costs. However, there is an important difference with the stochastic approach in both planning and overall costs. For instance, the stochastic model implemented battery systems for all district sizes and the deterministic models did not. In addition, if adequately formulated, a stochastic price-maker model is more robust to price changes and can achieve important economic benefits under different price scenarios.

Authors believe that by using adequate planning and operation approaches, like the one presented in this paper, and if the available regulation is DER friendly, it is likely that the role of the aggregator will continue to grow in importance, boosting the introduction of distributed energy resources and other related smart grid technologies.

\section{Acknowledgment}

The work of C. F. Calvillo was supported through an Erasmus Mundus Ph.D. Fellowship. The authors would like to express their gratitude to all partner institutions within the Erasmus Mundus Joint Doctorate Program in Sustainable Energy Technologies and Strategies (SETS) as well as to the European Commission for their support. 
C. Calvillo, A. Sánchez, J. Villar, F. Martín. Optimal planning and operation of aggregated distributed energy resources with market participation. Applied Energy. vol. 182, pp. 340-357, November 2016. [Online: August 2016] JCR impact factor: 7.182 (2016)

Christian F. Calvillo would like to thank José Portela, Andrés Ramos and Santiago Moreno from the Institute for Research in Technology (IIT), Madrid, Spain, for their valuable feedback and comments.

\section{References}

[1] R. Cossent, T. Gómez, and P. Frías, "Towards a future with large penetration of distributed generation: Is the current regulation of electricity distribution ready? Regulatory recommendations under a European perspective," Energy Policy, vol. 37, no. 3, pp. 11451155, Mar. 2009.

[2] K. M. Muttaqi, A. D. T. Le, J. Aghaei, E. Mahboubi-Moghaddam, M. Negnevitsky, and G. Ledwich, "Optimizing distributed generation parameters through economic feasibility assessment," Applied Energy, vol. 165, pp. 893-903, Mar. 2016.

[3] A. Sanchez-Miralles, T. Gomez San Roman, I. Fernandez, and C. Calvillo, "Business Models Towards the Effective Integration of Electric Vehicles in the Grid," IEEE Intelligent Transportation Systems Magazine, vol. 6, no. 4, pp. 45-56, winter 2014.

[4] L. Brange, J. Englund, and P. Lauenburg, "Prosumers in district heating networks - A Swedish case study," Applied Energy, vol. 164, pp. 492-500, Feb. 2016.

[5] OMIE, "Guía de acceso al mercado." Accessed July 14, 2016. http://www.omie.es/files/guia_omie noviembre_2015.pdf

[6] G. Cardoso, M. Stadler, M. C. Bozchalui, R. Sharma, C. Marnay, A. Barbosa-Póvoa, and P. Ferrão, "Optimal investment and scheduling of distributed energy resources with uncertainty in electric vehicle driving schedules," Energy, vol. 64, pp. 17-30, Jan. 2014.

[7] H. Pandžić, J. M. Morales, A. J. Conejo, and I. Kuzle, "Offering model for a virtual power plant based on stochastic programming," Applied Energy, vol. 105, pp. 282-292, May 2013. 
C. Calvillo, A. Sánchez, J. Villar, F. Martín. Optimal planning and operation of aggregated distributed energy resources with market participation. Applied Energy. vol. 182, pp. 340-357, November 2016. [Online: August 2016] JCR impact factor: 7.182 (2016)

[8] M. Shabanzadeh, M.-K. Sheikh-El-Eslami, and M.-R. Haghifam, "The design of a riskhedging tool for virtual power plants via robust optimization approach," Applied Energy, vol. 155, pp. 766-777, Oct. 2015.

[9] M. Houwing, G. Papaefthymiou, P. W. Heijnen, and M. D. Ilić, "Balancing wind power with virtual power plants of micro-CHPs," in PowerTech, 2009 IEEE Bucharest, 2009, pp. $1-7$.

[10]T. G. Werner and R. Remberg, “Technical, economical and regulatory aspects of Virtual Power Plants," in Third International Conference on Electric Utility Deregulation and Restructuring and Power Technologies, 2008. DRPT 2008, 2008, pp. 2427-2433.

[11]D. T. Nguyen and L. B. Le, "Risk-Constrained Profit Maximization for Microgrid Aggregators With Demand Response," IEEE Transactions on Smart Grid, vol. 6, no. 1, pp. 135-146, Jan. 2015.

[12]M. Honarmand, A. Zakariazadeh, and S. Jadid, "Integrated scheduling of renewable generation and electric vehicles parking lot in a smart microgrid," Energy Conversion and Management, vol. 86, pp. 745-755, Oct. 2014.

[13]N. Mahmoudi, T. K. Saha, and M. Eghbal, "Modelling demand response aggregator behavior in wind power offering strategies," Applied Energy, vol. 133, pp. 347-355, Nov. 2014.

[14]A. Yoza and T. Funabashi, "Optimal scheduling method of controllable loads in DC-smart house with deregulated electricity market," in Future Energy Electronics Conference (IFEEC), 2013 1st International, 2013, pp. 681-685.

[15]F. Glover, “Tabu Search-Part I,” ORSA Journal on Computing, vol. 1, no. 3, pp. 190206, Aug. 1989.

[16]R. Herranz, A. Munoz San Roque, J. Villar, and F. A. Campos, "Optimal Demand-Side Bidding Strategies in Electricity Spot Markets," IEEE Transactions on Power Systems, vol. 27, no. 3, pp. 1204-1213, Aug. 2012. 
C. Calvillo, A. Sánchez, J. Villar, F. Martín. Optimal planning and operation of aggregated distributed energy resources with market participation. Applied Energy. vol. 182, pp. 340-357, November 2016. [Online: August 2016] JCR impact factor: 7.182 (2016)

[17]REE (Electric Grid of Spain, Spanish TSO), "Red Eléctrica de España - Sistema de información del operador del sistema (Electric Grid of Spain - System's operator information system)," Accessed March 18, 2015. http://www.esios.ree.es/web-publica/

[18] OMIE (market operator of the Iberic system), "OMIE - Acceso a ficheros/Datos (OMIE access to files/data)," Accessed March 18, 2015. http://www.omie.es/aplicaciones/datosftp/datosftp.jsp

[19]K. Richa, C. W. Babbitt, G. Gaustad, and X. Wang, "A future perspective on lithium-ion battery waste flows from electric vehicles," Resources, Conservation and Recycling, vol. 83, pp. 63-76, Feb. 2014.

[20]L. A. Wolsey and G. L. Nemhauser, Integer and Combinatorial Optimization, 1 edition. New York; Chichester: Wiley-Interscience, 1999.

[21]Red Electrica de España (Electric Grid of Spain, Spanish TSO), "Proyecto INDEL - Atlas de la demanda eléctrica española (INDEL project -atlas of Spanish electric demand)," $\begin{array}{llll}\text { Accessed June } & 11,2014 .\end{array}$ http://www.ree.es/sites/default/files/downloadable/atlas_indel_ree.pdf

[22] European Commission - Joint Research Centre, "Photovoltaic Geographical Information System - Interactive Maps.” Accessed April 24, 2015. http://re.jrc.ec.europa.eu/pvgis/apps4/pvest.php

[23]Endesa, “Endesa Online," Accessed June 15, 2015. https://www.endesaonline.com/ES/hogares/index.asp

[24]Iberdrola, "Destino de tu factura - Iberdrola hogares" Accessed June 15, 2015. https://www.iberdrola.es/clientes/hogar/info/factura/factura-electricidad/destino-factura

[25]C. F. Calvillo, A. Sanchez, and J. Villar, "Distributed energy generation in smart cities," in 2013 International Conference on Renewable Energy Research and Applications (ICRERA), 2013, pp. 161-166. 
C. Calvillo, A. Sánchez, J. Villar, F. Martín. Optimal planning and operation of aggregated distributed energy resources with market participation. Applied Energy. vol. 182, pp. 340-357, November 2016. [Online: August 2016] JCR impact factor: 7.182 (2016)

[26]IDAE - Instituto para la Diversificación y Ahorro de la Energía (Spanish institute for energy savings and diversification), "Análisis del consumo energético del sector residencial en España: Informe Final (Analysis of energy consumption of the residential sector in Spain: Final Report)," July 2011. Accessed November 11, 2014. http://www.idae.es/uploads/documentos/documentos_Informe_SPAHOUSEC_ACC_f68 291a3.pdf

[27]A. Baillo, M. Ventosa, M. Rivier, and A. Ramos, "Optimal offering strategies for generation companies operating in electricity spot markets," IEEE Transactions on Power Systems, vol. 19, no. 2, pp. 745-753, May 2004.

[28] MathWorks "k-means clustering | Matlab kmeans" Accessed September 18, 2015 http://se.mathworks.com/help/stats/kmeans.html

[29] MathWorks "Line Simplification | File Exchange Matlab" Accessed September 18, 2015 http://www.mathworks.com/matlabcentral/fileexchange/21132-linesimplification/content/dpsimplify.m

[30]P. J. Rousseeuw, "Silhouettes: A graphical aid to the interpretation and validation of cluster analysis," Journal of Computational and Applied Mathematics, vol. 20, pp. 53-65, Nov. 1987.

[31]MathWorks "Silhouette plot | MATLAB Silhouette" Accessed September 18, 2015. http://es.mathworks.com/help/stats/silhouette.html

[32] A. Ugedo, E. Lobato, A. Franco, L. Rouco, J. Fernandez-Caro, J. de-Benito, J. Chofre, and J. De-la-Hoz, "Stochastic model of residual demand curves with decision trees," in IEEE Power Engineering Society General Meeting, 2003, 2003, vol. 2, p. -984 Vol. 2.

[33] S. Vázquez, P. Rodilla, and C. Batlle, "Residual demand models for strategic bidding in European power exchanges: Revisiting the methodology in the presence of a large penetration of renewables," Electric Power Systems Research, vol. 108, pp. 178-184, Mar. 2014. 
C. Calvillo, A. Sánchez, J. Villar, F. Martín. Optimal planning and operation of aggregated distributed energy resources with market participation. Applied Energy. vol. 182, pp. 340-357, November 2016. [Online: August 2016] JCR impact factor: 7.182 (2016)

[34]C. G. Baslis and A. G. Bakirtzis, "Optimal yearly scheduling of generation and pumping for a price-maker hydro producer," in Energy Market (EEM), 2010 7th International Conference on the European, 2010, pp. 1-6.

[35]C. F. Calvillo, A. Sánchez-Miralles, and J. Villar, "Assessing low voltage network constraints in distributed energy resources planning," Energy, vol. 84, pp. 783-793, May 2015.

[36]J. A. M. Sousa, F. Teixeira, and S. Faias, "Impact of a price-maker pumped storage hydro unit on the integration of wind energy in power systems," Energy, vol. 69, pp. 3-11, May 2014.

[37] S. Shafiee, P. Zamani-Dehkordi, H. Zareipour, and A. M. Knight, "Economic assessment of a price-maker energy storage facility in the Alberta electricity market," Energy, vol. 111, pp. 537-547, Sep. 2016.

[38]P. Zou, Q. Chen, Q. Xia, G. He, C. Kang, and A. J. Conejo, "Pool equilibria including strategic storage," Applied Energy, vol. 177, pp. 260-270, Sep. 2016.

[39] “How Long Do Solar Electric PV Panels Last? |CAT Information Service.” Accessed June 18, 2016. http://info.cat.org.uk/questions/pv/life-expectancy-solar-pv-panels.

[40]“How Long Should a Heat Pumps Last in My Home?" Heat Pumps Halifax, March 19, 2014. http://www.heatpumpshalifax.ca/long-heat-pumps-last/.

[41]“COPs, EERs, and SEERs - How Efficient Is Your Air Conditioning System? :: Power Knot:" Accessed June 18, 2016. http://www.powerknot.com/how-efficient-is-your-airconditioning-system.html.

[42] Calvillo, C. F., A. Sánchez-Miralles, and J. Villar. "Energy Management and Planning in Smart Cities." Renewable and Sustainable Energy Reviews 55 (March 2016): 273-87. doi:10.1016/j.rser.2015.10.133.

[43]IPCC. Special Report on Renewable Energy Sources and Climate Change Mitigation. Edited by Ottmar Edenhofer, Rafael Pichs-Madruga, Youba Sokona, Kristin Seyboth, 
C. Calvillo, A. Sánchez, J. Villar, F. Martín. Optimal planning and operation of aggregated distributed energy resources with market participation. Applied Energy. vol. 182, pp. 340-357, November 2016. [Online: August 2016] JCR impact factor: 7.182 (2016)

Patrick Matschoss, Susanne Kadner, Timm Zwickel, et al. United Kingdom and New York, NY, USA: Cambridge University Press, 2011.

[44] World Energy Council, "World Energy Perspective, Cost of Energy Technologies" Accessed June $18,2016.2$ https://www.worldenergy.org/wpcontent/uploads/2013/09/WEC_J1143_CostofTECHNOLOGIES_021013_WEB_Final.p df.

[45]How much do smart meters cost? Emeter. http://www.emeter.com/smartgridwatch/2010/how-much-do-smart-meters-cost/ [accessed 16.09.15].

[46] Cinco Días, “El 43\% de los clientes eléctricos está ya en el mercado liberalizado.” [Online]. Available:

http://cincodias.com/cincodias/2014/07/01/empresas/1404239492_758383.html. [Accessed: 21-Jun-2016].

[47]F. A. Campos, A. M. S. Roque, E. F. Sánchez-Úbeda, and J. P. González, "Strategic Bidding in Secondary Reserve Markets," IEEE Transactions on Power Systems, vol. 31, no. 4, pp. 2847-2856, Jul. 2016.

[48]F. Martin-Martínez, A. Sánchez-Miralles, and M. Rivier, "A literature review of Microgrids: A functional layer based classification," Renewable and Sustainable Energy Reviews, vol. 62, pp. 1133-1153, Sep. 2016.

[49]F. Martin-Martínez, A. Sánchez-Miralles, and M. Rivier, "Prosumers' optimal DER investments and DR usage for thermal and electrical loads in isolated microgrids". Electric Power Systems Research,” Electric Power Systems Research, vol., no., pp.-, 2016-12-31.

[50]"PV power estimate information." [Online]. Available: http://re.jrc.ec.europa.eu/pvgis/apps4/PVcalchelp_en.html\#Section_2. [Accessed: 14-Jul2016].

[51]"Pages - Energy Consumption of Tanks and Vats." [Online]. Available: http://www.spiraxsarco.com/Resources/Pages/Steam-Engineering-Tutorials/steam- 
C. Calvillo, A. Sánchez, J. Villar, F. Martín. Optimal planning and operation of aggregated distributed energy resources with market participation. Applied Energy. vol. 182, pp. 340-357, November 2016. [Online: August 2016] JCR impact factor: $7.182(2016)$

engineering-principles-and-heat-transfer/energy-consumption-of-tanks-and-vats.aspx

[Accessed: 14-Jul-2016].

[52] Cristian A. Díaz, José Villar, Fco. Alberto Campos, M. Ángel Rodríguez, A new algorithm to compute conjectured supply function equilibrium in electricity markets, Electric Power Systems Research, Volume 81, Issue 2, February 2011, Pages 384-392, ISSN 0378-7796, http://dx.doi.org/10.1016/j.epsr.2010.10.002.

[53]Cristian A. Díaz, Fco. Alberto Campos, José Villar, M. Ángel Rodríguez, Endogenous computation of conjectured supply functions with network constraints, Electric Power Systems Research, Volume 90, September 2012, Pages 117-125, ISSN 0378-7796, http://dx.doi.org/10.1016/j.epsr.2012.03.008.

[54]M. Diekerhof, S. Vorkampf and A. Monti, "Distributed optimization algorithm for heat pump scheduling," IEEE PES Innovative Smart Grid Technologies, Europe, Istanbul, 2014

pp.

$1-6$.

doi: 10.1109/ISGTEurope.2014.7028943

[55]P. Mancarella, "Distributed multi-generation options to increase environmental efficiency in smart cities," 2012 IEEE Power and Energy Society General Meeting, San Diego, CA, 2012, pp. 1-8. doi: 10.1109/PESGM.2012.6345129

[56]J. Villar, C. A. Díaz, P. González and F. A. Campos, "Wind and solar integration with plug-in electric vehicles smart charging strategies," 11th International Conference on the European Energy Market (EEM14), Krakow, 2014, pp. 1-6. doi: 10.1109/EEM.2014.6861265 